\title{
Interlinked Contracts: An Empirical Study
}

\author{
Hui-wen Koo, Chen-ying Huang and Kamhon Kan*
}

October 22, 2009

\begin{abstract}
This study investigates the contractual relationship between farmers and sugar mills in colonial Taiwan. Our investigation is based on a model of interlinked contracts, which is adapted from Gangopadhyay and Sengupta (1987). The validity of our model's predictions is verified by analyzing a data set consisting of contracts between Taiwan's cane farmers and sugar mills during the period of Japanese occupation. Our data suggest that the contractual relationship is consistent with a second best scenario, where the interest rates charged by sugar mills on cash loans to farmers are set in order to prevent diversion of funds to non-production uses.
\end{abstract}

JEL classification code: O12, O13

Keywords: interlinked contracts, credit, sugar industry, trader-cumlender, second best contracts

\section{Introduction}

Interlinkage, a contractual arrangement between two parties ${ }^{1}$ that combines transactions across multiple markets, is prevalent in the agrarian sector of

*Department of Economics, National Taiwan University and Institute of Economics, Academia Sinica. We thank Yan-shin Chen, Yi-chun Chen and Cheng-tao Tang for their very capable research assistance. Correspondence: Hui-wen Koo, Department of Economics, National Taiwan University, 21 Hsu Chow Road, Taipei, Taiwan 100. e-mail: hkoo@ntu.edu.tw

${ }^{1}$ There are also cases of a more complicated three-cornered interlinkage exchange. For instance, Bhalla (1976) and Bardhan and Udry (1999) both provided examples of this kind. 
many developing economies. ${ }^{2}$ More often than not, credit is one of the dealings that is linked. There are various explanations why interlinkage is often an observed pattern of credit transactions. According to Ray (1998), interlinkage can either help avoid laws that ban explicit usury by hiding the actual amount of interest, prevent strategic defaults, or increase the efficient surplus between the contracting parties. This paper, studying interlinked contracts in Colonial Taiwan where usury was not banned and defaults were not likely, is motivated by the third explanation.

In the literature there are theoretical results on how efficiency is reached through interlinkage, e.g. Gangopadhyay and Sengupta (1987). They considered the popular phenomenon in developing countries where a middleman serves as the sole buyer of crops in a local region, and sells in a competitive market. The middleman also provides loans to his farmers. Gangopadhyay and Sengupta (1987) demonstrated how the interest rate and the purchase price of crops are optimally interlinked so that the middlemen can induce the efficient level of production, while holding the farmers' utility to their reservation level. Their model yields a surprising prediction that for production loans, the middleman will charge an interest rate lower than the opportunity cost of his capital.

The Gangopadhyay and Sengupta (1987) study is rooted in a debate in the literature concerning the rate of interest in rural credit markets. For instance, Bhaduri (1977) argued that a lender is in a position to charge a usurious rate without worrying about the default risk, because the farmer borrower highly values his collateral. Bottomley (1963) also argued for a high interest rate, but for an opposite reason. He was concerned about the marketability and the possible declining value of collateral, and suggested that a high interest rate in the village simply reflects a default risk. When solving the optimal contract for a landlord-cum-lender, Braverman and Stiglitz (1982) showed

\footnotetext{
${ }^{2}$ The discussions regarding interlinked contracts have many dimensions. To name a few, Bell and Udry (1997) and Chakrabarty and Chaudhuri (2001) examined the interaction between formal and informal credit institutions where interlinkage is often observed in the latter. Basu and Chaudhuri (2000) analyzed the strict superiority of interlinkage when the tenant has limited liability. Sadoulet (1992) studied interlinked contracts in Latin America in the creation of a dualistic agrarian structure. Bell (1988) provided a very detailed discussion about interlinked transactions.
} 
that the landlord will set an interest rate to encourage tenants to borrow more (less), when the increased borrowing induces more (less) efforts from tenants. In a village survey in east India, Bardhan and Rudra (1978) found that $43 \%$ of surveyed tenants took production loans from landlords, and $37 \%$ of these cases had a zero interest rate. In response to multifaceted discussion, Gangopadhyay and Sengupta (1987) showed the logic of having a low interest rate for a trader-cum-lender.

Although the interlinked contract is prevalent, it is rarely investigated empirically. This is likely to be due to the absence of data or records on such contracts between middlemen and farmers. In this paper, we contribute to the literature by collecting and analyzing a unique data set, which consists of contracts between sugar mills and cane growers in Taiwan during the Japanese colonial time.

In Taiwan during the Japanese colonial period, there are two types of farmers, namely dry-field and paddy farmers, who had different opportunity costs of growing sugar cane. To accommodate the existence of farmers with differential opportunity costs, we extend the model of Gangopadhyay and Sengupta (1987) to derive theoretical predictions. With this extension, the prediction by Gangopadhyay and Sengupta (1987) that the interest rate charged by the sugar mills to their cane growers is lower than the former's opportunity cost of capital still holds. Also, this prediction is empirically supported by our data. Nevertheless, we demonstrate that the contract terms in our data are not entirely consistent with some other predictions assuming optimal contracting. In particular, although the interest rate is observed to be lower than the opportunity cost of the sugar mills, it is not as low as what predicted by optimal contracting. This implies that all cane growers underinvested. Motivated by the fact that sugar mills were not setting their interest rate at the optimal level, and our observation of a very sluggish movement of interest rates, we propose a second best scenario to describe contracting between sugar cane farmers and mills.

After obtaining a loan from a sugar mill, a farmer might have an incentive to divert the proceeds for other uses because the rate of interest is lower than the prevailing market rate. This possibility might explain why contracts between sugar cane farmers and mills deviated from what predicted by optimal 
contracting. Under the second best contractual arrangement, the interest rate is assumed to be constrained from below and for sugar mills optimality is attained by setting the purchase price of cane. To examine the validity of our second best explanation, we employ a regression analysis. By and large, the regression results are consistent with the predictions of the second best contracting.

The rest of the paper is organized as follows. Section 2 provides background information about our data. Section 3 presents a theoretical model, extended from Gangopadhyay and Sengupta (1987). Section 4 studies comparative statics and section 5 presents the empirical investigation. The final section concludes.

\section{Background}

\subsection{Sugar Mills}

In the Japanese colonial era (1895-1945), sugar was the most important product in Taiwan. Among tens of traditional sugar mills, which contributed less than $3 \%$ of output, 40 or so new-styled mills run by Japanese capitalists were the main producers. Sugar was made from cane. The contracts between the new-styled mills and cane farmers are the focus of this paper.

From 1905 onwards, each new-styled mill became a monopsonist in its local region, thanks to the Japanese Governor-General's regulations. ${ }^{3}$ Every year, before the planting season, mills would announce their future contracts for cane, which would take more than one year to grow. Considering the terms, farmers were free to choose cane or other crops to plant. Most sugar produced in Taiwan was exported to Japan, where the Japanese and other foreign manufacturers competed to sell it. Mills in Taiwan were thus like the middlemen considered by Gangopadhyay and Sengupta (1987). They were price searchers when dealing with farmers and price takers when operating in the downstream sugar market. Mills provided their cane farmers with loans. Cane trade and financing were therefore interlinked.

\footnotetext{
${ }^{3} \mathrm{~A}$ mill had hundreds of or thousands of farmers growing cane for it. So farmers were in no position to bargain the terms of contract with the mill.
} 
The interest rate of loans, along with the future price of cane, was stated in the contract. The term "sugar year" was used in contracts to define the time period. For instance, sugar for the 1930/31 sugar year referred to sugar manufactured from the end of 1930 until April of 1931. The cane of this sugar year therefore referred to crops planted between the fall of 1929 and the spring of 1930. The contract for the 1930/31 sugar year was announced sometime in the middle of 1929, when the mill was still uncertain about how the sugar market would turn out in $1931,{ }^{4}$ and farmers had to estimate their revenues from other crops in $1930,{ }^{5}$ if they decided not to plant cane. Their expectation, instead of the realization, of prices will be taken into account when studying the data in section 5 .

\subsection{Loans}

According to Taiwan Sugar Statistics (1911-1943), there were four uses of loans: working capital, fertilizers, seeds and others. Figure 1 depicts the average amount borrowed by a farmer with 1 chia $^{6}$ of land between the 1920/21 and 1939/40 sugar years. Fertilizers and working capital were by far the dominant components of loans. This contradicts the view by Yanaihara (1929, p.328), who speculated farmers borrowed to consume, and hence locked themselves into planting cane for mills. Yanaihara (1929) viewed these farmers as "bonded labor." Figure 1, however, provides evidence that farmers borrowed to invest. Both fertilizers and seeds were given in-kind. Working capital, al-

\footnotetext{
${ }^{4}$ The literature suggests that the price uncertainty of the crop can be one explanation of the existence of credit-product interlinkage. Fabella (1992) considers this uncertainty and shows that when the trader is risk-neutral and the farmer is risk-averse, the interlinked contract Pareto dominates pure trading with which the farmer borrows from the financial market and sells his produce in the product market. Chaudhuri and Gupta (1995) show that even when the trader and the farmer have equal risk-aversion coefficients, so long as the trader's opportunity cost of capital is lower than the market interest rate, the interlinked contract stills Pareto dominates pure trading. Their findings justify the interlinked contracts that mills offer to cane farmers in our case.

${ }^{5}$ Because it took about a year if the farmer chose to plant other crops, the farmer's revenue from other crops in 1930 reflected the opportunity cost of planting cane in the fall of 1929 .

${ }^{6} 1$ chia $\approx 1$ hectare.
} 


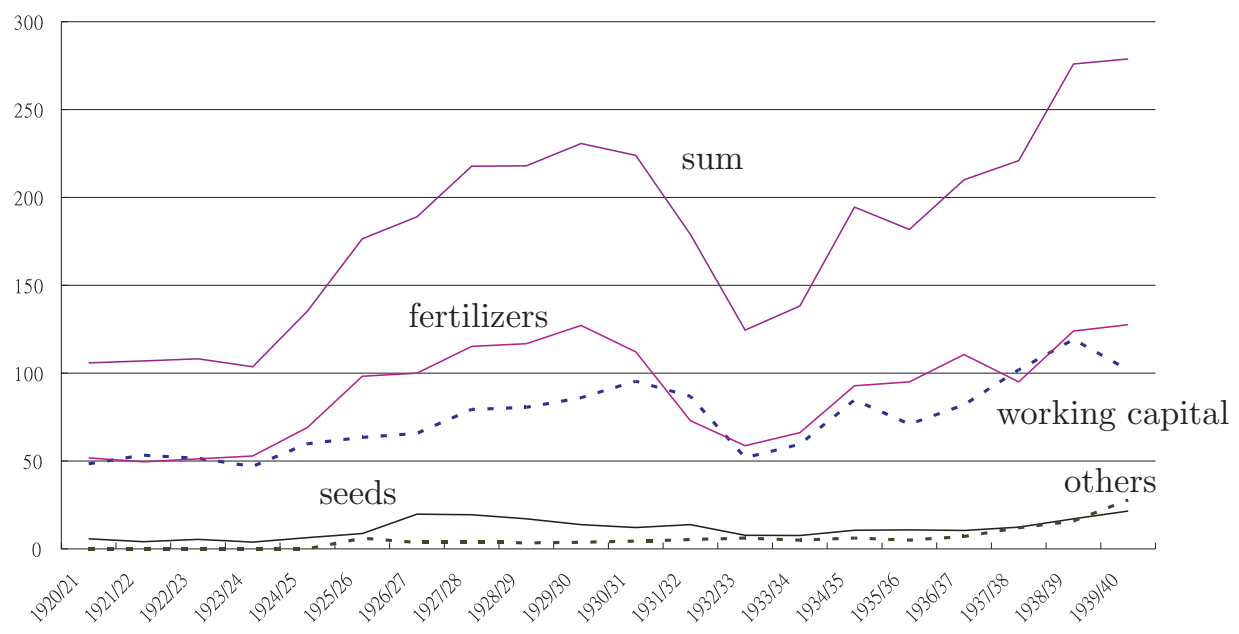

Figure 1: Average Loan (yuan/chia)

Note: The yuan was the monetary unit at that time.

Source: Taiwan Sugar Statistics (1911-1943).

though given in cash, was strictly required to be used for cane plantation. If a farmer was caught using the loan for other purposes, he was subject to a fine two to three times the amount of his loan.

Other provisions of loans were mostly to tenant farmers to help them pay their rents. Almost all other crops ripened in a much shorter time than cane. If tenant farmers planted crops other than cane, they could easily pay their landlords rents at harvest time. When planting cane, they had to rely on mills to finance their rent payments. In short, tenant farmers borrowed to plant cane, not the other way around.

\subsection{Price Discrimination}

In the contracts we collected, mills took advantage of their monopsony positions and price discriminated among farmers. The discrimination usually occurred based on farmers' opportunity costs of planting cane. For instance, rice, a high-valued crop, could only grow in paddies. Many mills thus offered higher cane prices to farmers with paddies than to farmers with dry fields.

The interest rate, however, was never differentiated among farmers in a 
mill's purchasing zone, probably because loans were transferable. If interest rates were differentiated, farmers qualifying for the lowest rate would borrow and then transfer their loans to other farmers. On the other hand, the mill helped or monitored the cutting of cane at harvest time. There was no way to transfer cane from dry fields to paddies to get better terms. Because of these observations, in the next section, the instruments a mill could use to design an interlinked contract are a common interest rate and two cane prices, one paid to the paddy farmers and the other paid to the dry-field farmers.

\section{The Model}

To match our data, we consider the case in which there are two types of land: dry fields and paddies. We use subscript 1 for dry fields and 2 for paddies. Paddy farmers have a higher opportunity cost when planting cane because alternatively they can grow rice. Therefore, we denote $A_{1}$ and $A_{2}$ as the opportunity costs of these two types of farmers, with $A_{1}<A_{2}$. A mill designs a contract: $\left\{P_{1}, P_{2} ; i\right\}$, where $P_{1}$ and $P_{2}$ denote the purchase prices of cane to farmers of each type and $i$ is their common interest rate.

The harvest of cane depends on its production, which in our data is mostly financed by the mill. Let $L_{t}$ denote the production loan a type $t$ farmer takes. The production function of cane, $f\left(L_{t}\right)$, is assumed to be the same for both types of farmers, ${ }^{7}$ and satisfies the following standard assumption:

Assumption 1. $f(0)=0, f^{\prime}>0, f^{\prime \prime}<0, \lim _{L_{t} \rightarrow 0^{+}} f^{\prime}\left(L_{t}\right) \rightarrow \infty, \lim _{L_{t} \rightarrow \infty} f^{\prime}\left(L_{t}\right)=$ 0 .

Let $v$ denote the dollar value per unit of cane to a mill, and $r$ the mill's opportunity cost of capital. The maximal joint surplus a mill and a type $t$ farmer can earn together is: $S^{*} \equiv \max _{L_{t}} v f\left(L_{t}\right)-(1+r) L_{t}$. Note that to

\footnotetext{
${ }^{7}$ If we drop this assumption, all propositions, except proposition 3, remain valid. Proposition 3 will be reversed when the paddy is much more productive to grow cane than the dry-field, and hence generates a much larger joint surplus between the mill and the farmer than the dry-field. In this case, $i_{1}^{*}$ could be larger than $i_{2}^{*}$ and proposition 3 will be reversed. However, the empirical implication of proposition 3 that not both types of farmers will underinvest remains unchanged. Our data will still reject this changed proposition 3 in the first best model, and will point us to the second best model.
} 
maximize the joint surplus, the marginal product of the production loan must equal $(1+r) / v$. Clearly, only farmers with $A_{t} \leq S^{*}$ are worth recruiting. To make the analysis interesting and our prediction sharp, we assume that $A_{1}, A_{2}<S^{*}$. That is, both types are worth recruiting. In the analysis, we shall further concentrate on the case that it is optimal for a mill to recruit both types of farmers, and correspondingly in the empirical investigation, we shall exclude all cases that only contain one type of farmers. ${ }^{8}$

We first consider a benchmark case where the mill can differentiate interest rates among farmers of different types. We denote in this case $i_{t}^{*}$ and $P_{t}^{*}$ as the interest rate and the cane price tailored, respectively, for a type $t$ farmer. From the literature, the following is known.

Proposition 1. (Gangopadhyay and Sengupta (1987)) To recruit a farmer, in the optimal contract:

$$
\frac{1+i_{t}^{*}}{1+r}=\frac{P_{t}^{*}}{v}=\frac{A_{t}}{S^{*}} .
$$

The intuition why this is the optimal contract is as follows. The farmer's profit is $P_{t}^{*} f\left(L_{t}\right)-\left(1+i_{t}^{*}\right) L_{t}$. To maximize his profit, he will take the loan up to the point where the marginal product of the loan is equal to $\left(1+i_{t}^{*}\right) / P_{t}^{*}$. Because $\left(1+i_{t}^{*}\right) / P_{t}^{*}=(1+r) / v$ in $(1)$, the loan he takes exactly maximizes the joint surplus, i.e., $S^{*}$ is earned. On the other hand, (1) implies the farmer's share of the joint surplus is $A_{t} / S^{*}$, and hence he takes away exactly his reservation $A_{t}$. Because the maximal joint surplus is produced and the farmer's profit is held down to his reservation level, the contract is certainly optimal for the mill.

The upshot is that instead of charging farmers usurious rates, a mill will optimally suppress $i_{t}^{*}$ below $r$ because only farmers with $A_{t} / S^{*} \leq 1$ are worth recruiting. The loss on the loan is compensated for by setting the cane price $P_{t}^{*}$ lower than the market value of cane $v$. In the end, farmers keep no surplus, and an optimal contract is efficient. In the following, we shall extend this

\footnotetext{
${ }^{8}$ There are 26 (out of 404) samples that only dry field farmers plant cane, but considering that some samples have to be dropped in any case because they do not contain full information, we actually only drop 7 extra samples to exclude cases of only one type of farmers.
} 
result by Gangopadhyay and Sengupta (1987) to the case when the interest rate is not differentiated.

\subsection{A Farmer's Problem}

Given the mill's terms, $\left\{i, P_{t}\right\}$, a type $t$ farmer has to decide how much to borrow to maximize his profit, $\pi_{f t}$ :

$$
\max _{L_{t}} \pi_{f t}=P_{t} f\left(L_{t}\right)-(1+i) L_{t} .
$$

Note that in $\pi_{f t}$, the subscript $f$ stands for farmers. Under assumption 1, the optimal loan is uniquely determined by the FOC:

$$
f^{\prime}\left(L_{t}\right)=\frac{1+i}{P_{t}}
$$

\subsection{The Mill's Problem}

We first consider the given interest rate $i$, and study how $P_{t}$ is determined. To maximize its profit from a type $t$ farmer, $\pi_{m t}$, where the subscript $m$ stands for mills, the mill faces two constraints: the incentive compatibility (IC) constraint (2), and the individual rationality (IR) constraint, i.e., the farmer has to get no less than $A_{t}$. In brief, a mill's problem is as follows:

$$
\begin{gathered}
\max _{P_{t}, L_{t}} \pi_{m t}=v f\left(L_{t}\right)-(1+r) L_{t}-P_{t} f\left(L_{t}\right)+(1+i) L_{t} \\
\text { s.t. } f^{\prime}\left(L_{t}\right)=\frac{1+i}{P_{t}} \\
P_{t} f\left(L_{t}\right)-(1+i) L_{t} \geq A_{t} .
\end{gathered}
$$

Note that the mill's profit is simply the joint surplus minus the farmer's profit.

We now turn to how the optimal interest rate is determined in the first best contract. Let $\lambda \in(0,1)$ stand for the proportion of paddy farmers in a mill's local area. Denote $\pi_{m t}^{*}$ as the maximized value of $\pi_{m t}$ in problem (3). When the mill recruits both types of farmers to plant cane, the interest rate is set to maximize its average profit:

$$
\max _{i} \pi_{M}^{F B}=(1-\lambda) \pi_{m 1}^{*}+\lambda \pi_{m 2}^{*} .
$$

We denote the first best interest rate by $i^{F B}$. 


\subsection{First Best Interest Rate}

We will show the following in this subsection. (1) The optimal interest rate in the first best contract is less than the mill's opportunity cost of capital. In other words, the prediction of Gangopadhyay and Sengupta (1987) still holds. (2) In the first best contract, it cannot be the case that all farmers underinvest. For ease of exposition, all proofs are relegated to the appendix.

Proposition 2. The mill will optimally charge an interest rate lower than the opportunity cost of its capital, i.e., $i^{F B}<r$.

The intuition behind proposition 2 is this. If one type of farmer is more numerous than the other type, then the profit from the former is more important. Therefore, to recruit both types, the common interest rate will be closer to the optimal interest rate when only the more numerous type is recruited. In general, the common interest rate is therefore a weighted average of $i_{1}^{*}$ and $i_{2}^{*}$. By proposition $1, r>i_{2}^{*}>i_{1}^{*}$, because the opportunity costs of both types are less than the maximal joint surplus $S^{*}$. Hence, the optimal common interest rate, a weighted average of $i_{1}^{*}$ and $i_{2}^{*}$, must be less than $r$.

Now, if the optimal common interest rate is above $i_{1}^{*}$ and below $i_{2}^{*}$, intuitively, it is set too high for the dry-field farmers and too low for the paddy farmers. Hence, we have the following proposition.

Proposition 3. The dry-field farmer will underinvest, and the paddy farmer will overinvest.

\subsection{Cane Price}

The whole idea of interlinked trade is that the mill bears a loss when financing farmers' investments, and more than covers this loss by suppressing the cane price. Proposition 2 shows the first part of the previous sentence: the mill indeed bears a loss when financing farmers' investments by charging interest rates lower than the cost of capital. This subsection will establish the second part: the cane price increases with the interest rate, ceteris paribus. In other words, if the mill charges a lower interest rate (thus incurring a higher loss in financing farmers), the cane price has to be lower at the same time to make 
it worthwhile. We first impose an additional assumption and then formally state this:

Assumption 2. $-f\left(L_{t}\right) f^{\prime \prime}\left(L_{t}\right) /\left(f^{\prime}\left(L_{t}\right)\right)^{2}$ weakly increases in $L_{t}$.

Assumption 2 is satisfied when $f^{\prime \prime \prime}\left(L_{t}\right)$ is small. It is satisfied for any function with $f^{\prime \prime \prime}\left(L_{t}\right) \leq 0, \forall L_{t}$. For the functions with $f^{\prime \prime \prime}\left(L_{t}\right)>0, f\left(L_{t}\right)=\ln \left(L_{t}\right)$ and $f\left(L_{t}\right)=L_{t}^{\alpha}$ where $\alpha \in(0,1)$ satisfy assumption 2 .

Proposition 4. Under assumptions 1 and 2, ceteris paribus, in the optimal solution to (3), $\partial P_{t} / \partial i>0, \forall t$.

\subsection{The Second Best Model}

We now turn to model the second best option where some moral hazard exists. In the case where a mill's optimal first best interest rate $i^{F B}$ is lower than the market rate $r$, cane farmers will use a mill's loan to finance their other needs, or even take the arbitrage opportunity to lend money from the mill to others at the market rate. To prevent such opportunistic behavior, a mill has to monitor how its farmers make use of the loan, even when monitoring can be only imperfect. To accommodate this, let $q$ stand for the probability of a mill catching a cheating farmer. To increase $q$, a mill has to undertake more monitoring efforts. Denote $c(q)$ as the monitoring cost if the mill has probability $q$ of catching a farmer using the loan for other purposes. We assume $c(q)$ to be increasing and convex in $q$. In mills' contracts, it is frequently mentioned that a cheating farmer who has been caught, has to pay a higher interest rate on his loan. Therefore, let $k$ denote this penalty rate. To make the cheating farmer really pay the price for his opportunistic behavior, the penalty rate has to be higher than the market rate; thus we have:

$$
k>r \text {. }
$$

Note that $k$ in our model is exogenously determined, for otherwise the mill can set an arbitrarily high $k$ to deter the misuse of loans by the farmers. However, this is usually not possible either because social customs impose some limit on the possible $k$ or farmers have limited liability. To simplify the analysis, we assume farmers to be risk-neutral. In this case, a farmer 
is deterred from arbitraging when his expected interest rate charged by the mill is higher than the market rate, i.e.:

$$
q k+(1-q) i \geq r
$$

To deter farmers from arbitraging, (5) should be added as a constraint to the first best model in (4). Moreover, to reflect the monitoring cost, a mill's objective in (4) should be modified to: ${ }^{9}$

$$
\max _{i, q} \pi_{M}^{S B}=\max _{i, q} \pi_{M}^{F B}-c(q) .
$$

Note that when moral hazard is taken into account, whatever the second best rate the mill chooses, it should still choose two cane prices optimally by solving (3). Let $i^{S B}$ denote the optimal interest rate in the second best model. We first show that the optimal second best rate is higher than the optimal first best rate. This is intuitive because if we marginally increase the interest rate from the first best level, a mill's gross profit (excluding the monitoring cost) is not affected to the first order. However, this increase moves the interest rate closer to the market rate $r$. Then, according to the no arbitrage condition (5), $q$ can be decreased and hence the monitoring cost can be reduced, which is good for the mill.

Proposition 5. $i^{S B}>i^{F B}$.

Hence, when a mill considers its farmers' moral hazard problem, it will raise the interest rate above $i^{F B}$. Clearly, no farmer will borrow from the mill if the rate is raised above $r$. This upper bound constraint on the interest rate does not have to be spelled out in our formulation, because it is automatically satisfied as the following proposition shows. Intuitively, it serves no purpose

\footnotetext{
${ }^{9} \mathrm{An}$ alternative way to mitigate the moral hazard problem is to impose a maximum amount on the loan without monitoring the farmer's use of the loan. However, one could derive that if this measure is taken, the farmer will always borrow the maximum amount and this investment in cane cultivation will be subject to the market interest rate rather than the mill's interest rate. In this situation, lending to farmers at a rate lower than the market rate incurs loss to the mill's capital without offering any incentive to farmer's investment. The mill will hence make no loans to farmers and cannot take any advantage of an interlinked contract.
} 
for the mill to increase the second best interest above the market rate because when the second best rate is as high as the market rate, farmers have no incentive to arbitrage. Hence, increasing the second best rate further above the market rate only moves the second best rate even farther away from the first best rate. This reduces gross profit (excluding the monitoring cost) without reducing the monitoring cost and is not worthwhile.

Proposition 6. (a) $i^{S B} \leq r$. (b) $i^{S B}<r$ if $d \pi_{M}^{F B} /\left.d i\right|_{i=r}<-c^{\prime}(0) /(k-r)$.

\section{Comparative Statics}

In this section we list all the comparative statics results of the second best model when moral hazard is taken into account. The proofs are not as straightforward but the results are consistent with intuition. We will interpret the results intuitively before every proposition. Some of the comparative results do not have a definite sign and hence cannot be empirically tested. For this reason, we only state the results that have a definite sign. They serve as a basis for the empirical tests in the next section. Note that all these results also hold for the first best model, because if we assume the monitoring cost $c(q)=0, \forall q$, then the second best model (6) will degenerate into the first best model and all the derivation of the comparative statics will naturally go through. The empirical distinction between the first best model and the second best model does not lie in their different comparative statics results, but rather in different levels of interest rate implied by them. Section 5.2.2 will fully discuss this point.

\subsection{Cane Value}

Our first set of results pertains to the change in the cane value. Intuitively, when the cane value increases, the mill can make more profit and so it will encourage the farmers to plant more cane. This is indeed the case, as we first show that when the cane value increases, if one increases the interest rate, the marginal impact on the mill's gross profit (excluding the monitoring cost) decreases. (See lemma 5 in Appendix.) Because of this, increasing the interest rate becomes less profitable. Hence, as we show below in the following 
proposition, the higher the cane value, the lower the interest rate the mill sets so as to induce the farmers to take more loans to plant cane.

Proposition 7. In the optimal solution to (6), $d i^{S B} / d v<0$ and $d L_{t} / d v>$ $0, t=1,2$.

\subsection{The Market Interest Rate}

As for the market rate, if it increases, the mill cannot make as much profit and hence it may want to increase the second best rate so as to discourage farmers from planting cane. Hence, one would expect that the comparative results would go in the opposite direction to those in the case where the value of cane increases. This is roughly correct except that there is an additional complication. When the market rate increases, if the mill does not change the second best interest rate, to deter the farmers from arbitraging, the monitoring cost has to be higher by (5). If the monitoring cost rises fast enough, then this gives the mill an additional incentive to raise its second best interest rate. We show in the following proposition that if the monitoring cost function indeed increases fast enough, then when the market rate increases, the mill increases its second best rate as well. Moreover, when doing so, farmers are induced to take up fewer production loans.

Proposition 8. When $c_{q q} \geq c_{q} /(1-q)$ in the discussion range, in the optimal solution to (6), $d i^{S B} / d r>0$. Moreover, in the second best contract, $d L_{t} / d r<$ 0 , when $d i^{S B} / d r>0$.

\subsection{Paddy Ratio}

As for the comparative statics result when the proportion of paddy farmers changes, the data strongly suggest that the second best rate increases when the proportion of paddy farmers is higher, or $d i^{S B} / d \lambda>0$.

When it is the case that $d i^{S B} / d \lambda>0$, the following proposition shows that the price in the contract increases and the production loan is smaller when the proportion of paddy farmers is higher. The reason why the price increases is because the parameter $\lambda$ does not appear in the optimization problem of (3). Hence, when $\lambda$ increases, if the interest rate increases as well, 
then by interlinkage, the price in the contract has to be higher as already shown in proposition 4. As for why the production loan becomes smaller, this is because when the interest rate increases in problem (3), it becomes more costly to induce a production loan of the same size.

Proposition 9. When $d i^{S B} / d \lambda>0$ in the optimal solution to (6), (a) $d P_{t} / d \lambda>0, t=1,2$ and (b) $d L_{t} / d \lambda<0, t=1,2$.

\section{Empirical Study}

In this section we first introduce the data sources of our empirical analysis. This is followed by a statistical test of the first best model against its second best counterpart. It turns out that our analysis lends support to the second best model. We then further test the second best model via a test about the comparative statistics derived in Section 4.

\subsection{Data}

Our data are from different sources. They are mainly compiled from reports or documents published by the Colonial Government of Taiwan. The cane price and the interest rate in this study are quoted directly from mills' contracts documented in Sugar Industry Addendum (1928-1944). Sugar Industry Addendum (1928-1944) started to publish these contracts from the 1929/30 sugar year onward. Because data from other sources are not available in some of the years during this period, our study is restricted to the 1930/31-1939/40 sugar years. There are 42 mills listed in Sugar Industry Addendum (1928-1944). Because a small number of these mills did not start operation until very late in this period, we have an unbalanced panel. There is a total of 351 observations in our sample. The unit of observation is a mill's contract, which specifies the terms of transaction for each type (i.e., dry-field and paddy) of farmers.

The terms of a contract would vary with the value of the cane and farmers' opportunity costs (i.e., revenue of planting other crops, e.g., rice). As mentioned in section 2.1, in the middle of year $t-1$ when contemplating a contract pertaining to sugar year $t / t+1$, the mill had to take into consid- 
eration the cane value to be realized in year $t+1$ and farmers' expectation of rice prices in year $t$. Rice has two seasons in a year. We assume that in the middle of year $t-1$, a mill formed its expectation of future rice prices based on those in the two seasons of year $t-2$ when setting the terms of the contract. On the other hand, mills could rely on year $t-1$ 's futures market for the sugar price in year $t+1$. They could also have a rough idea about their cost of capital when they lent to farmers later on by observing the market interest rate in year $t-1$. Thus, in the empirical analysis, it seems reasonable that we link the rice price in year $t-2$, and the sugar price and the market interest rate in year $t-1$ to contract terms pertaining to sugar year $t / t+1 .^{10}$

We compute the value of cane from the price for Taiwanese sugar on the Osaka futures market, as documented in Taiwan Sugar Statistics (19111943). For the rice price, we use the price of Zailai rice as a proxy. This is because Zailai rice was the most popular rice species in Taiwan in the early 1930s. Data on Zailai rice prices are quoted from Taiwan Rice Annual (1934-1942). The fact that Zailai rice was gradually replaced by the more valuable Ponlai rice indicates that farmers' opportunity costs of planting cane increased over time. We will take this trend into account in regressions.

For the market rate of interest (denoted $r$ in the theoretical model), which is taken as a sugar mill's opportunity cost of funds lent to farmers, we use the lending rates of village credit unions as reported in the Taiwan Financial Annual (1934-1942). The lending rates of the village credit unions are a good proxy for the market interest rates because a mill could certainly lend to people who would borrow from village credit unions at the prevailing rate. $^{11}$

\footnotetext{
${ }^{10}$ This paper shies away from the issues of the uncertainty in the environment and does not deal with the expected utility function. To give readers a general idea about the inflation rate during this period, Taiwan's CPI was 189.17 in 1929 and 225.18 in 1939 (Wu (2005)). The average yearly inflation rate was about $2 \%$.

${ }^{11}$ We do not use the interest rates charged by commercial banks because in the colonial era, it was difficult for farmers to get loans from commercial banks, which gave loans mainly to corporations rather than farmers. There were some documentations on the interest rates between Taiwanese individuals in cities. However, probably because these rates were not charged to loans for agricultural purposes, but to loans involving higher default risks, they
} 


\subsection{The Optimality of the Common Interest Rate}

Both the first best and the second best models predict that the common interest rate has to be lower than the mill's opportunity cost of capital (propositions 2 and 6), whereas the first best model alone states that it cannot be optimal if all farmers underinvest (proposition 3). We test propositions 2 and 6 in section 5.2.1 and examine the validity of proposition 3 in section 5.2 .2 .

\subsubsection{Usurious Interest Rate?}

According to propositions 2 and 6, a mill charges an interest rate that is below its opportunity cost, rather than a usurious one. We examine the validity of this implication of propositions 2 and 6 using two strategies.

Firstly, we test the null hypothesis that a sugar mill's lending rate is equal to the market rate (i.e., $\mathrm{H}_{0}: i-r=0$ ) against the alternative hypothesis that the former rate is below the market rate (i.e., $\mathrm{H}_{1}: i-r<0$ ). Figure 2 plots the market rate $r$ along with the average interest rate that mills charged on working capital. In our data, the mean and standard deviation of $i-r$ are -0.1830 and 0.0072 . This implies that we can reject the null hypothesis that $i-r=0$ at conventional levels and accept the alternative hypothesis that $i-r<0$.

Secondly, Survey of Agricultural Financing (1941) provides further evidence that creditors in interlinked trades charge lower interest rates. Across five Chow $^{12}$ in Taiwan, 5,995 village families were interviewed at the end of 1940. Their loans were listed in a cross table according to interest rates and sources of loans. For instance, the surveyed farmers were recorded as having borrowed 505,508.05 yuan from sugar mills, of which 146,479.73 yuan was interest free and 338,267.82 yuan was at an annual rate below $7 \%$.

appeared higher than the rates charged by village credit unions. For instance, in 1929 while the monthly interest rate of the village credit union in Tainan Chow was $1.2 \%$, the personal loan rates in two main cities in Tainan Chow, namely, Tainan City and Chia-Yi City, were 1.5-2\% and 2-3\%, respectively ( Tainan Chow Statistics Book (1929, pp.292-3)). Since the rate of personal loans in the cities might overestimate a mill's cost of capital in the village, we do not use it for our market rate, either.

${ }^{12}$ Chow is the prefecture equivalent to the State. 


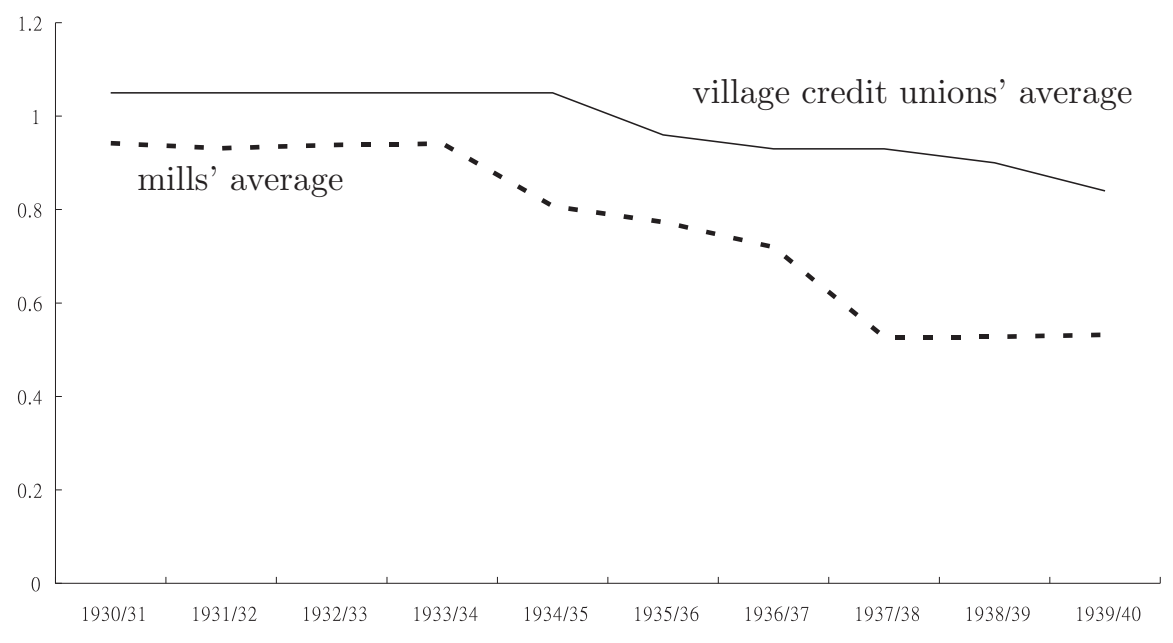

Figure 2: Monthly Interest Rate (\%)

According to whether loans were interlinked with other trades, we regroup the sources of these loans. The ones that fall into the category of interlinked traders include sugar mills, landowners, and middlemen of crops and pigs. The other sources consist of banks, trusts, credit unions, individual professional creditors, grocers and fertilizer vendors. Figure 3 plots the cumulative distribution functions of interest rates of the interlinked traders, banks, grocers and the remaining sources. In the sense of first-order stochastic dominance, the interest rate in the interlinked trades is smaller than that in pure financing. This is consistent with the prediction of our model.

The reason that we consider banks separately is that banks in the colonial era often followed the Governor-General's policy of lending at low rates. For instance, at the time of the survey, farmers in Tainan Chow still had huge debts owed to Kangyo Bank for the Chia-Nan irrigation project implemented in the 1920s and 1930s. According to Taiwan Financial Annual (19341942) (1940, pp. 170-71), this irrigation loan together with loans to aid post-earthquake reconstruction were all provided at low rates. Because the terms of bank loans might reflect government policies rather than free market forces, banks are considered separately.

A comparison between the interest rates of interlinked traders and banks 


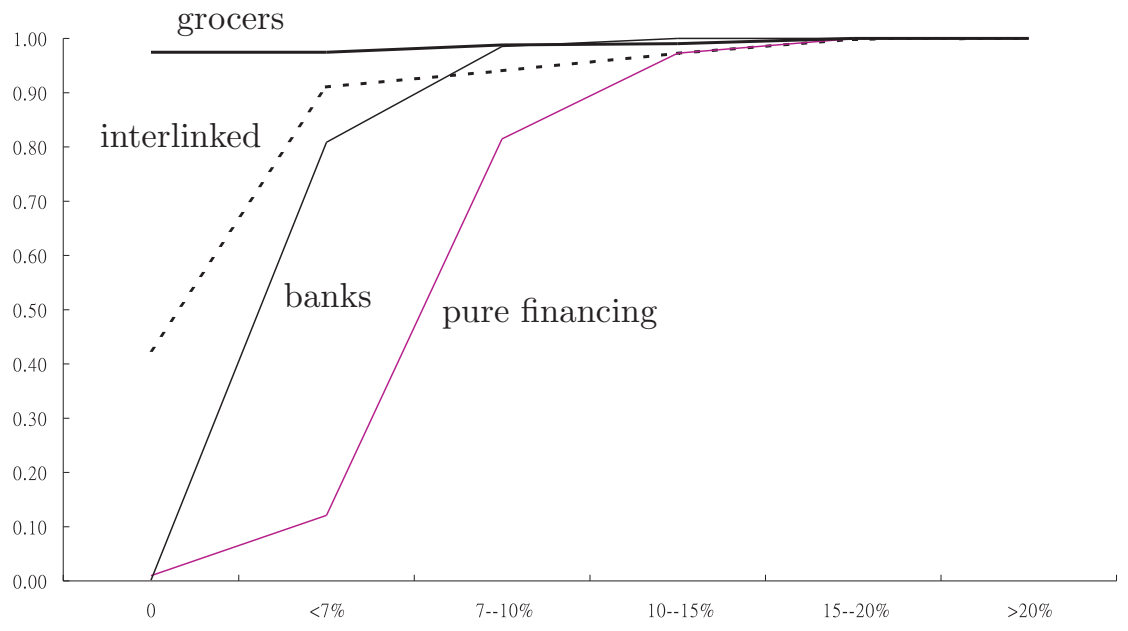

Figure 3: CDF of Annual Interest Rate

Source: Survey of Agricultural Financing (1941, pp. 8-13)

is informative. While $42 \%$ of linked loans were interest free, banks rarely provided loans free of interest even for loans granted under government directives. However, the bank's interest rates were not always higher. This is because while banks never charged a rate higher than $15 \%$, a few creditors in interlinked trades asked for a rate even higher than $20 \%$. We speculate that the high rates appearing in the interlinked trades were those for bad loans. For example, the contract of Taichung Mill in the 1940/41 sugar year stated that the monthly rate on working capital was $0.6 \%$. However, if a cane farmer failed to repay the loan at harvest time, the rate would be raised to $1.5 \%$. Interlinked loans in other trades may have had similar provisions. On the other hand, the delayed payment of loans on the Chia-Nan irrigation project was handled very differently. Civil Affairs Statistical Annual (1929-1938) documents loans of this irrigation project. In 1936, a bad loan of 3,536,517 yuan was owed to the Treasury. Instead of raising the interest rate for this loan, the Treasury waived the debtor of the interest payments.

Finally, $97.44 \%$ of loans to grocers were interest free. Loans to grocers were very short-term and not suitable for comparison with other much longerterm loans. 


\subsubsection{Negative Interest Rate?}

According to proposition 3, in the first best model, the paddy farmer will overinvest and the dry-field farmer will underinvest. So, by equation (2), the marginal product of a paddy farmer's loan, $(1+i) / P_{i}$, must be less than $(1+r) / v$, and the opposite holds for a dry-field farmer. It implies that:

$$
\begin{gathered}
\frac{v}{P_{1}}>\frac{1+r}{1+i}, \\
\frac{v}{P_{2}}<\frac{1+r}{1+i},
\end{gathered}
$$

with

$$
v=\left(P_{s}-c\right) \phi,
$$

where $P_{s}$ is the sugar price per 1,000 gin, ${ }^{13} c$ is the cost of producing 1,000 gin of sugar (payments to cane farmers excluded) and $1 / \phi$ is the cane-to-sugar conversion ratio, i.e., $\phi$ units of sugar is produced from one unit of cane.

To examine whether proposition 3 actually holds in the case of colonial Taiwan, let us take the Bridge-Head Mill as an illustrating example by applying its data to (7b). For Bridge-Head Mill in the 1930/31 sugar year, $P_{s}=121.7$ yuan (the 1928 future price of sugar) $c=25.58$ yuan and $\phi=0.1519$ (calculated from Taiwan Sugar Statistics (1911-1943)), such that $v=14.60$ yuan per 1,000 gin. On the other hand, in the contract, the highest cane price offered by Bridge-Head Mill in the 1930/31 sugar year was 5 yuan per 1,000 gin, and the annual interest rate was $12 \%$. (7b) will not hold unless $r \geq 227 \%$, which is unlikely. Alternatively, for $r<192 \%$, (7b) is satisfied only if $i<0$.

For other years, for (7b) to hold in the case of Bridge-Head Mill, the minimum $r$ ranges from $119 \%$ to $242 \%$, with an average of $190 \%$. For other mills, the minimum $r$ for (7b) is similar to that of Bridge-Head Mill and is also unreasonably high. Miao-Li Mill has the lowest minimum $r$, i.e., $69 \%$, which, however, is still too high to be realistic. The above calculation suggests that (7b) is unlikely to be satisfied in reality.

Next, we formally test $(7 \mathrm{a})$ and $(7 \mathrm{~b})$. Let $d_{t}=v / P_{t}-(1+r) /(1+i), t=$ 1,2 , and let $\bar{d}_{t}$ denote the average of $d_{t}$ over all mills and years. Our null

\footnotetext{
${ }^{13} 1$ gin $=0.6 \mathrm{~kg}$.
} 
hypotheses are that:

$$
\mathrm{H}_{0}^{1}: \bar{d}_{1} \geq 0 \text { and } \mathrm{H}_{0}^{2}: \bar{d}_{2} \leq 0 \text {. }
$$

We shall test these two hypotheses separately by means of a $t$-test. To reject the null hypotheses at the 5\% significance level, we must have $\tau_{1}<1.645$ and $\tau_{2}>-1.645$, where $\tau_{t}=\bar{d}_{t} / \sqrt{\operatorname{var}\left(d_{t}\right)}$. Based on our data, the test statistics are $\tau_{1}=34.88$ and $\tau_{2}=42.51$, implying that $\mathrm{H}_{0}^{1}$ is accepted and $\mathrm{H}_{0}^{2}$ is rejected.

In sum, the data suggest that all farmers underinvest. The interest rate charged by the mill is not the first best rate and could not be so unless it becomes negative.

Why did mills not consider a negative, or at least a $0 \%$, interest rate to increase profits? Recall from Figure 1 that there were two major uses of loans: fertilizers and working capital. A scrutiny of contracts reveals that loans on fertilizers were probably interest free. While the stated interest rate was said clearly to apply to loans on working capital and tenants' rent payments, no contract ever discussed how to calculate interest payments for fertilizer loans. Moreover, the samples of Survey of Agricultural Financing (1941) showed $28.98 \%$ of mills' loans were free of interest. Because loans on working capital clearly earned interest, from the amounts of the different loans plotted in Figure 1, we can safely infer fertilizer loans were interest free.

All contracts stated that fertilizer loans were given out in-kind, and mills would charge farmers no more than the cost. Taitung Mill went even further in subsidizing farmers' fertilizer loans. For instance, in the 1930/31 sugar year, the aboriginal cane farmers received $20 \%$ of their ammonium sulfate and $50 \%$ of their calcium superphosphate for free. ${ }^{14}$ This in fact made interest rates negative.

Working capital loans, unlike fertilizer loans, were lent in cash. If working capital loans were free of interest, or if the mill subsidized working capital loans, farmers would be induced to borrow to finance other needs as well. In section 2.2 , we mention that the contract carried a severe penalty clause

\footnotetext{
${ }^{14}$ This practice is in line with landlords sharing costs with tenants as found by Bardhan and Rudra (1978).
} 


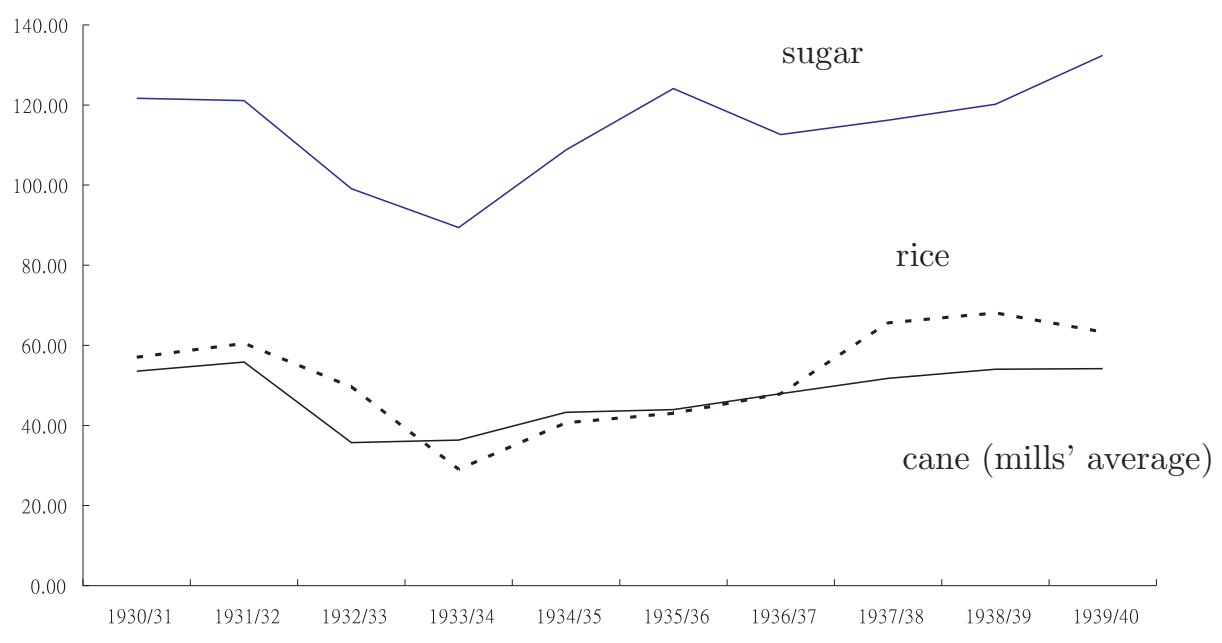

Figure 4: Prices

Note: The units of the sugar price and the Zailai paddy price are yuan/1,000 gin. The unit of the cane price is yuan/10,000 gin.

in case farmers switched the mill's loan to other uses. Mills were apparently concerned about whether their money was indeed invested in cane fields. If perfect monitoring was too costly, presumably mills would not lower interest rates in an unlimited manner. This explains why a negative interest rate dictated by (7b) would not be observed on working capital loans.

In summary, when loans were lent out in-kind, as the first best model predicts, the interest rate could be zero, or even negative. However, when loans were given in cash, with farmers' moral hazard problem in mind, the interest rate was not as low as the first best model boldly predicts.

There is one more evidence that leads to the rejection of the first best model. While section 3.2 describes how the first best interest rate should be determined in view of sugar prices and rice prices, in Figure 2 we observe sluggish movement of the interest rate and that the interest rate tracks the rate at the village credit unions closely. In contrast, cane prices move synchronously with sugar prices and rice prices, as can be seen in Figure 4. The co-movement is especially apparent during the early 1930s, when the interest rates of almost all mills remained flat from 1930/31 to 1934/35. 
If the mill is concerned whether its farmers will use their loans for other purposes, then it may be very cautious in setting an interest rate much lower than the farmers' alternative borrowing rate. This helps explain why the interest rate tracks the rate at the village credit unions closely, because farmers can always get loans at the village credit unions. ${ }^{15}$ This observation, along with the observation that the mill is very cautious in granting cash loans, leads us to reject the first best model and turn to the second best model.

\subsection{Testing of the Comparative Statics}

This section further tests the second best model in a regression framework. The four endogenous variables in a contract include the interest rate (denoted Interest $\mathrm{t}_{i t}^{\mathrm{m}}$ ), the purchase price of cane grown by paddy farmers (denoted Price ${ }_{i t}^{\mathrm{p}}$ ), the purchase price of cane grown by dry-field farmers (denoted $\operatorname{Price}_{i t}^{\mathrm{d}}$ ) and the production loans granted by a mill to farmers (denoted $\operatorname{Loan}_{i t}$ ). We explain these four endogenous variables using a set of exogenous variables. The regression models are specified as follows:

$$
y_{j i t}=\boldsymbol{x}_{i t} \boldsymbol{\beta}_{j}+\alpha_{j i}+\eta_{j t}+\epsilon_{j i t} ; \quad j=1,2,3,4
$$

where $y_{j i t}$ stands for the variables Interest $\mathrm{m}_{i t}^{\mathrm{m}}(j=1)$, Price ${ }_{i t}^{\mathrm{p}}(j=2)$, $\operatorname{Price}_{i t}^{\mathrm{d}}(j=3)$, and $\operatorname{Loan}_{i t}(j=4)$. The vector $\boldsymbol{x}_{i t}$ denotes a set of explanatory variables, which include cane value (denoted CaneValue ${ }_{i t}$ ), the interest rate charged by village credit unions (denoted Interest ${ }_{i t}^{c}$ ), paddy proportion (denoted Paddy $\%_{i t}$ ), proportion of Ponlai in a prefecture (denoted Ponlai $\%{ }_{i t}^{1}$ and Ponlai $\%{ }_{i t}^{2}$ ), revenue of Zailai (denoted Zailai ${ }_{i t}^{1}$ and Zailai ${ }_{i t}^{2}$ ), and revenue of dry rice (denoted DryRice ${ }_{i t}^{1}$ and DryRice $\left.{ }_{i t}^{2}\right) .{ }^{16}$ To explain Loan $_{i t}$, in addition to the above mentioned explanatory variables, we use the

\footnotetext{
${ }^{15}$ In our research period, the number of village credit unions increased from 311 to 417 in Taiwan and their annual loans to farmers increased from 42 million yuan to 95 million yuan. In an average year, mills' loans to farmers was $27 \%$ of village credit unions' loans to farmers (Taiwan Province: Statistical Summary of the Past 51 Years (1946, pp.1108-9)). So we could safely assume the market for loans to be competitive and a mill to take the market interest rate as given when making its contracts.

${ }^{16}$ See Table 1 for the summary statistics and definition of these variables.
} 
variable $\mathbf{I}_{i t}^{\text {non-rent }}$, which is a dummy variable indicating the absence of a loan granted by a mill for the purpose of paying a farmer's land rent. ${ }^{17}$ Because our focus is on loans to farmers for production purposes, we want to restrict our attention to contracts where loans are not used for paying rents. It is noted that $i$ is a subscript for mills and $t$ is a subscript for years, and $\alpha_{j i}$ and $\eta_{j t}$, respectively, are mill and year fixed effects; and $\epsilon_{j i t}$ is a normally distributed error term. That is, we have a fixed effects specification, which accounts for time-invariant heterogeneity in the regression models. ${ }^{18}$

The variables Zailai ${ }_{i t}^{1}$ and Zailai ${ }_{i t}^{2}$ are proxies for a paddy farmer's opportunity cost, which is what he expects to obtain if he grew rice instead. Ponlai rice is a more valuable rice species, which gradually became prevalent in our sample period (see Figure 5). It was first planted in northern Taiwan (as indicated by the top three lines of Figure 5), and was gradually planted in the south (the two thin dotted lines) and on the east coast (the two thick dotted lines). A paddy farmer's opportunity cost would increase when he started to consider Ponlai rice as a substitute crop for cane. The variables Ponlai $\%{ }_{i t}^{1}$ and Ponlai $\%{ }_{i t}^{2}$ control for the increasing trend of an average paddy farmer's opportunity cost. As for the dry-field farmers, although there was no good substitute for cane, we use the revenue of dry rice (denoted DryRice ${ }_{i t}^{1}$ and DryRice ${ }_{i t}^{2}$ ) to proxy their opportunity cost. Finally, to calculate cane value (denoted CaneValue ${ }_{i t}$ ), we use formula (8). The descriptive statistics of the variables used in our empirical analysis are exhibited in Table 1.

It is noted that, in the regression models for Interest $t_{i t}^{\mathrm{m}}$, Price ${ }_{i t}^{\mathrm{p}}, \operatorname{Price}_{i t}^{\mathrm{d}}$, and $\operatorname{Loan}_{i t}$, we use only exogenous variables as explanatory variables, without imposing a structural specification. That is, they are reduced form models.

The theoretical model suggests that the interest rate that a mill charged on loans to a farmer, the sugar cane prices, and the amount of loans a mill gives out to a farmer are all inter-related, and these variables are endoge-

\footnotetext{
${ }^{17}$ We have experimented with putting the variable $I_{i t}^{\text {non-rent }}$ into the right-hand side the regression models for Interest $t_{i t}^{\mathrm{m}}$, Price ${ }_{i t}^{\mathrm{p}}$, and Price ${ }_{i t}^{\mathrm{d}}$. The estimation results pertaining to these regression models do not change significantly.

${ }^{18}$ The fixed effects specification enables us to control for endogeneity arising from timeinvariant heterogeneity which is correlated with a regressor in a model.
} 
Table 1: Summary Statistics

\begin{tabular}{|c|c|c|c|}
\hline Variable & Definition & Mean & Std. Dev. \\
\hline Interest $_{i t}^{\mathrm{m}}$ & $\begin{array}{l}\text { Interest rate charged by a mill on loans to a } \\
\text { farmer. }\end{array}$ & 0.745 & 0.186 \\
\hline $\operatorname{Price}_{i t}^{\mathrm{p}}$ & $\begin{array}{l}\text { Purchase price of sugar cane grown by paddy farm- } \\
\text { ers. }\end{array}$ & 4.859 & 1.144 \\
\hline $\operatorname{Price}_{i t}^{\mathrm{d}}$ & $\begin{array}{l}\text { Purchase price of sugar cane grown by dry-field } \\
\text { farmers. }\end{array}$ & 4.666 & 0.835 \\
\hline $\operatorname{Loan}_{i t}$ & $\begin{array}{l}\text { Loans obtained by a farmer from a mill for pro- } \\
\text { duction purposes. }\end{array}$ & 211.121 & 103.131 \\
\hline Interest $_{i t}^{c}$ & Credit market interest rate. & 0.928 & 0.130 \\
\hline CaneValue $_{i t}$ & Cane value. & 11.196 & 1.713 \\
\hline Paddy $\%_{i t}$ & Proportion of paddy farmers in a mill's prefecture. & 0.460 & 0.214 \\
\hline Zailai $_{i t}^{1}$ & $\begin{array}{l}\text { Average revenue of Zailai farmers in a mill's pre- } \\
\text { fecture in the first rice season. }\end{array}$ & 221.102 & 60.418 \\
\hline Zailai $_{i t}^{2}$ & $\begin{array}{l}\text { Average revenue of Zailai farmers in a mill's pre- } \\
\text { fecture in the second rice season. }\end{array}$ & 190.370 & 57.183 \\
\hline Ponlai $\%{ }_{i t}^{1}$ & $\begin{array}{l}\text { Proportion of Ponlai fields among rice fields in a } \\
\text { mill's prefecture in the first rice season. }\end{array}$ & 0.432 & 0.197 \\
\hline Ponlai $\%{ }_{i t}^{2}$ & $\begin{array}{l}\text { Proportion of Ponlai fields among rice fields in a } \\
\text { mill's prefecture in the second rice season }\end{array}$ & 0.291 & 0.184 \\
\hline $\operatorname{DryRice}_{i t}^{1}$ & $\begin{array}{l}\text { Average revenue of dry rice farmers in a mill's pre- } \\
\text { fecture in the first rice season. }\end{array}$ & 100.516 & 55.661 \\
\hline $\operatorname{DryRice}_{i t}^{2}$ & $\begin{array}{l}\text { Average revenue of dry rice farmers in a mill's pre- } \\
\text { fecture in the second rice season. }\end{array}$ & 118.929 & 34.332 \\
\hline $\mathrm{I}_{i t}^{\text {non-rent }}$ & $\begin{array}{l}\text { Dummy variable indicating the absence of a loan } \\
\text { granted by a mill to cover farmers' land rent. }\end{array}$ & 0.812 & 0.391 \\
\hline Mills & 42 & & \\
\hline Observations & 351 & & \\
\hline
\end{tabular}




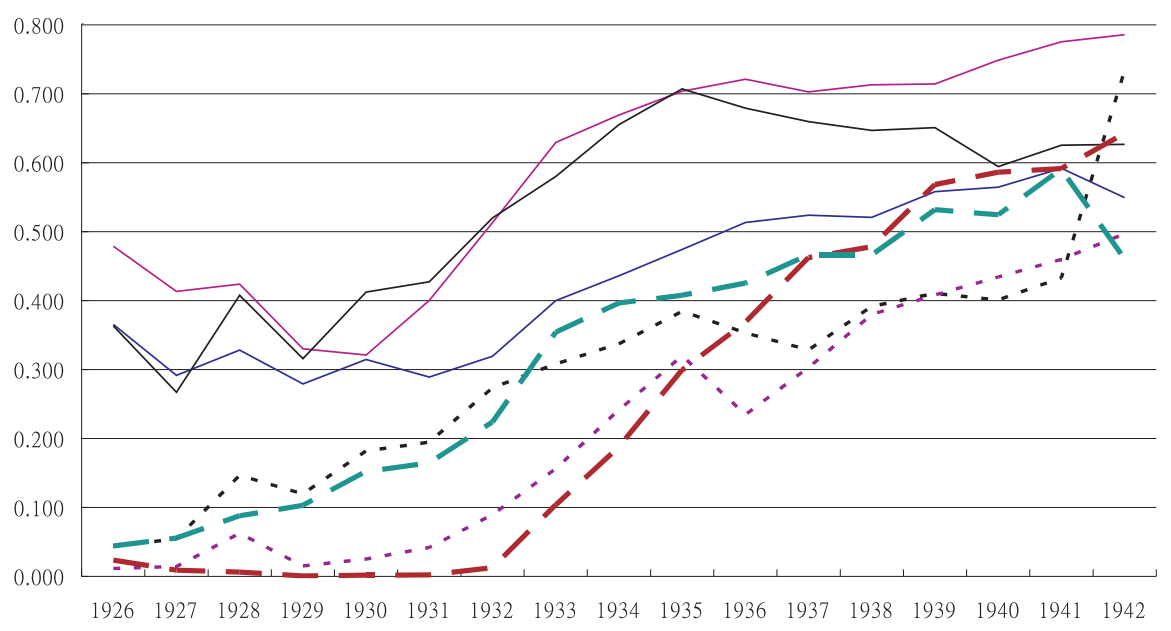

Figure 5: The Proportion of Ponlai Rice Area in 7 Prefectures

Note: The proportion is Ponlai rice area divided by area planted with either Ponlai or Zailai rice.

Source: Taiwan Rice Annual (1934-1942).

nous variables. For example, our model predicts that there exists a positive relationship between a mill's purchase price of cane and the interest rate of its loans to a farmer (i.e., Proposition 4). This implies that to examine the relationship among these variables a simultaneous equations system should be estimated. However, estimating such a system requires the imposition of exclusion restrictions. For example, to identify the impact of the purchase price of cane on a mill's interest rate, we need to have at least one exogenous variable which affects the purchase price but not the interest rate. Unfortunately, such exogenous variables are not available in our data. That is, parameters of the system of simultaneous equations are not identifiable. Because of this, we give up investigating the relationship among these endogenous variables. To examine the validity of our theoretical model, instead, we exploit the model's comparative statics and examine the relationship between the endogenous variables and some exogenous variables by estimating a set of reduced form equations.

Actually, what the comparative statics correspond to is the relationship between the endogenous variable and the exogenous variable exhibited in 
the reduced form models, where the coefficient of a variable depicts the total effect of an exogenous variable on an endogenous variable. This total effect includes the direct effect of the exogenous variable and the indirect effect. By contrast, in a simultaneous equations system, the coefficient of an exogenous variable represents only the direct effect. ${ }^{19}$

The empirical results of our regression analyses are reported in Table 2. According to proposition 7, cane value has a negative effect on the mill's interest rates and a positive effect on the amount of loans granted by a mill to farmers. However, contrary to our model's predictions, we find that the value of cane (denoted CaneValue ${ }_{i t}$ ) does not have a statistically significant impact on a mill's interest rate and the amount of loans granted, as suggested by the variable's $t$-statistics (i.e., 0.72 and -0.07 , respectively). This is mainly because of the fact that CaneValue $i t$ does not have much cross-sectional variation since all mills sold sugar to Japan. Therefore, they all faced the same price of sugar and sugar prices only changed from year to year. If we drop the year dummies, it is indeed the case that the value of cane has a significant negative effect on a mill's interest rate (the coefficient is -0.0036 and the standard error is 0.0021 ) and has a significant positive effect on the amount of loans granted (the coefficient is 10.2739 and the standard error is $1.8020) \cdot{ }^{20}$

${ }^{19}$ To illustrate this point, we use a generic simultaneous equations system.

$$
\begin{aligned}
& y_{1}=\alpha_{1} y_{2}+\beta_{11} x_{1}+\beta_{12} x_{2}+\epsilon_{1}, \\
& y_{2}=\alpha_{2} y_{1}+\beta_{21} x_{1}+\beta_{23} x_{3}+\epsilon_{2} .
\end{aligned}
$$

Its reduced form can be written as

$$
\begin{aligned}
& y_{1}=\frac{\alpha_{1} \beta_{21}+\beta_{11}}{1-\alpha_{1} \alpha_{2}} x_{1}+\frac{\beta_{12}}{1-\alpha_{1} \alpha_{2}} x_{2}+\frac{\alpha_{1} \beta_{23}}{1-\alpha_{1} \alpha_{2}} x_{3}+\frac{1}{1-\alpha_{1} \alpha_{2}} \epsilon_{1}+\frac{\alpha_{1}}{1-\alpha_{1} \alpha_{2}} \epsilon_{2}, \\
& y_{2}=\frac{\alpha_{2} \beta_{11}+\beta_{21}}{1-\alpha_{1} \alpha_{2}} x_{1}+\frac{\alpha_{2} \beta_{12}}{1-\alpha_{1} \alpha_{2}} x_{2}+\frac{\beta_{23}}{1-\alpha_{1} \alpha_{2}} x_{3}+\frac{1}{1-\alpha_{1} \alpha_{2}} \epsilon_{2}+\frac{\alpha_{2}}{1-\alpha_{1} \alpha_{2}} \epsilon_{1} .
\end{aligned}
$$

The coefficient $\beta_{11}$ represents the direct effect of $x_{1}$ on $y_{1}$, and the total effect of $x_{1}$ is equal to $\frac{\alpha_{1} \beta_{21}+\beta_{11}}{1-\alpha_{1} \alpha_{2}}$.

${ }^{20}$ Without putting time dummies in the regressions, the coefficients of CaneValue ${ }_{i t}$ have a statistically significant impact on both Interest ${ }_{i t}^{\mathrm{m}}$ and Loan $_{i t}$. This suggests that the three variables share a common year effect. 
Table 2: Interest Rate and Cane Price

\begin{tabular}{|c|c|c|c|c|}
\hline & Interest ${ }_{i t}^{\mathrm{m}}$ & $\operatorname{Price}_{i t}^{\mathrm{p}}$ & $\overline{\operatorname{Price}_{i t}^{\mathrm{d}}}$ & $\operatorname{Loan}_{i t}$ \\
\hline Constant & $\begin{array}{l}0.7196^{* *} \\
(0.1069)^{\dagger}\end{array}$ & $\begin{array}{c}0.5480 \\
(1.0695)\end{array}$ & $\begin{array}{c}2.5492^{* *} \\
(0.9376)\end{array}$ & $\begin{array}{c}195.8661^{*} \\
(116.9305)\end{array}$ \\
\hline CaneValue $_{i t}$ & $\begin{array}{c}0.0041 \\
(0.0058)\end{array}$ & $\begin{array}{c}0.0605 \\
(0.0578)\end{array}$ & $\begin{array}{c}0.0654 \\
(0.0507)\end{array}$ & $\begin{array}{c}-0.42512 \\
(6.1770)\end{array}$ \\
\hline Interest ${ }_{i t}^{c}$ & $\begin{array}{c}0.1110^{* *} \\
(0.0547)\end{array}$ & $\begin{array}{c}0.1423 \\
(0.5468)\end{array}$ & $\begin{array}{c}1.4113^{* *} \\
(0.4793)\end{array}$ & $\begin{array}{c}-99.36304^{*} \\
(58.4365)\end{array}$ \\
\hline Paddy $\%_{i t}$ & $\begin{array}{c}0.0593^{* *} \\
(0.0295)\end{array}$ & $\begin{array}{c}0.9096^{* *} \\
(0.2954)\end{array}$ & $\begin{array}{c}0.1740 \\
(0.2589)\end{array}$ & $\begin{array}{c}104.5405^{* *} \\
(31.5080)\end{array}$ \\
\hline Ponlai $\% \frac{1}{i t}$ & $\begin{array}{c}-0.2606^{* *} \\
(0.0597)\end{array}$ & $\begin{array}{c}0.2647 \\
(0.5975)\end{array}$ & $\begin{array}{c}0.5540 \\
(0.5238)\end{array}$ & $\begin{array}{l}-66.0210 \\
(63.8096)\end{array}$ \\
\hline Ponlai $\%_{i t}^{2}$ & $\begin{array}{c}0.0512 \\
(0.0486)\end{array}$ & $\begin{array}{c}3.2329^{* *} \\
(0.4865)\end{array}$ & $\begin{array}{c}1.0127^{* *} \\
(0.4265)\end{array}$ & $\begin{array}{c}78.3746 \\
(51.9062)\end{array}$ \\
\hline $\operatorname{Zailai}_{i t}^{1}$ & $\begin{array}{c}-0.0006^{* *} \\
(0.0002)\end{array}$ & $\begin{array}{c}0.0031 \\
(0.0022)\end{array}$ & $\begin{array}{c}-0.0030 \\
(0.0019)\end{array}$ & $\begin{array}{c}0.4605^{* *} \\
(0.2338)\end{array}$ \\
\hline $\mathrm{Zailai}_{i t}^{2}$ & $\begin{array}{l}-0.0003 \\
(0.0002)\end{array}$ & $\begin{array}{c}0.0105^{* *} \\
(0.0022)\end{array}$ & $\begin{array}{c}0.0028 \\
(0.0019)\end{array}$ & $\begin{array}{c}0.13528 \\
(0.2378)\end{array}$ \\
\hline $\operatorname{DryRice}_{i t}^{1}$ & $\begin{array}{l}-0.0002 \\
(0.0002)\end{array}$ & $\begin{array}{l}-0.0019 \\
(0.0019)\end{array}$ & $\begin{array}{c}-0.0005 \\
(0.0017)\end{array}$ & $\begin{array}{l}-0.0252 \\
(0.2074)\end{array}$ \\
\hline $\operatorname{DryRice}_{i t}^{2}$ & $\begin{array}{c}0.0001 \\
(0.0002)\end{array}$ & $\begin{array}{c}-0.0056^{* *} \\
(0.0019)\end{array}$ & $\begin{array}{c}0.0013 \\
(0.0016)\end{array}$ & $\begin{array}{c}-0.1130 \\
(0.2003)\end{array}$ \\
\hline $\mathrm{I}_{i t}^{\text {non-rent }}$ & & & & $\begin{array}{c}-13.9478 \\
(15.8843)\end{array}$ \\
\hline $\begin{array}{l}\text { Time fixed Effects } \\
\text { Mill fixed Effects } \\
\text { R-squared } \\
\text { Observation Number }\end{array}$ & 0.9509 & 0.8031 & 0.7728 & 0.6066 \\
\hline
\end{tabular}

†Standard errors in parentheses.

${ }^{* *}$ Statistically significant at the $5 \%$ level. ${ }^{*}$ Statistically significant at the $10 \%$ level. 
Our theoretical model implies that one cannot make unconditional predictions on the effect of the market interest rate on the amount of loans granted by a mill to farmers (i.e., $\mathrm{d} L_{t} / \mathrm{d} r$ ), the effects of the proportion of paddy farmers on a mill's sugar cane purchase price (i.e., $\mathrm{d} P_{t} / \mathrm{d} \lambda$ ), or the effect of the paddy farmer ratio on the amount of loans granted by a mill (i.e., $\mathrm{d} L_{t} / \mathrm{d} \lambda$ ). Nevertheless, it has implications on the signs of these effects conditional on the relationship among certain variables in the model.

According to our theoretical model, under a mild condition, we have $d i^{S B} / d r>0$. If $d i^{S B} / d r$ is positive, then $d L_{t} / d r$ is negative (see proposition 8.) Our empirical result does show that there is a positive and statistically significant effect of the market interest rate on a mill's interest rate. The coefficient estimate is 0.1110 and is significant at the $10 \%$ level. Because our empirical results suggest that $d i^{S B} / d r$ is positive, according to our theoretical model it is predicted that $d L_{t} / d r$ is negative. This prediction is borne out by our empirical results. The coefficient estimate of the market interest rate is -99.36304, which is negative and statistically significant at the $10 \%$ level in the model for $\operatorname{Loan}_{i t}$ (see column 4 in Table 2).

While our theoretical model does not have an unambiguous unconditional predictions on the signs of the effects of the proportion of paddy farmers on a mill's sugar cane purchase price (i.e., $\mathrm{d} P_{t} / \mathrm{d} \lambda$ ), it is predicted (see proposition 9) that $\mathrm{d} P_{t} / \mathrm{d} \lambda>0$ when $\mathrm{d} i^{S B} / \mathrm{d} \lambda>0$. Our finding of a statistically significant positive coefficient estimate of Paddy $\%_{i t}$ in the regression results of the model for a mill's interest rate (i.e., $\mathrm{d} i{ }^{S B} / \mathrm{d} \lambda$ is estimated to be 0.0593 ) implies that the effect of the paddy farmer ratio should have a positive effect on mills' sugar cane purchase prices. This prediction is consistent with the positive coefficient estimate of the paddy farmer ratio in the regression models for the dry-field cane price and the paddy field cane price, respectively. The coefficient estimate of the paddy farmer ratio in the model for the dry-field cane price is statistically insignificant (0.1740), whereas that in the model for the paddy cane price is statistically significant at the $5 \%$ level (0.9096).

Furthermore, our theoretical model suggests that the effect of the paddy farmer ratio on total loans granted by a mill is negative (i.e., $\mathrm{d} L_{t} / \mathrm{d} \lambda<$ $0, t=1,2$, see proposition 9 ) when the effect of the paddy farmer ratio on 
the interest rate charged by a mill is positive (i.e., $\mathrm{d} i^{S B} / \mathrm{d} \lambda>0$ ). However, we are not able to test this implication because of the absence of information on the two types of loans. In the data, we only observe a weighted average of loans taken up by paddy and dry-field farmers, i.e.,

$$
L=(1-\lambda) L_{1}+\lambda L_{2}
$$

What complicates our investigation of the theoretical prediction is that even if both $\mathrm{d} L_{1} / d \lambda$ and $\mathrm{d} L_{2} / d \lambda$ are negative, the sign of $\mathrm{d} L / d \lambda$ remains ambiguous. $^{21}$

We are not going to discuss the results pertaining to other explanatory variables. This is because the signs of coefficients of these variables are not informative in gauging the validity of our theoretical model and there is no clear interpretation of the coefficients of these variables.

\section{Conclusion}

In summary, this paper uses Taiwanese sugar mills' contracts in the 1930s to test the theory of interlinked contracts. Our findings support Gangopadhyay and Sengupta (1987) who proposed that when a production loan is interlinked with other trade, the creditor is willing to ask for an interest rate lower than its cost of capital, and the loss in lending will be more than compensated by profit in the other trade. However, we find that the interest rate is not as low as the model predicts. We conjecture that it is because too low an interest rate would encourage farmers to borrow more than their investment needs for cane growing, to satisfy their other financial needs. The creditor's low interest rate will hence not be worthwhile. In cases where this moral hazard problem was not severe, mills were found to be very willing to lower their interest rates. When mills lent in-kind (fertilizer or seed), they were willing to set the interest rate at zero or even negative.

\footnotetext{
${ }^{21}$ With

$$
\frac{\mathrm{d} L}{\mathrm{~d} \lambda}=-L_{1}+L_{2}+(1-\lambda) \frac{\mathrm{d} L_{1}}{\mathrm{~d} \lambda}+\lambda \frac{\mathrm{d} L_{2}}{\mathrm{~d} \lambda}
$$

it is straightforward to see that the sign of $\mathrm{d} L / \mathrm{d} \lambda$ depends on the relative sizes of $L_{1}$ and $L_{2}$ even if both $\mathrm{d} L_{1} / d \lambda$ and $\mathrm{d} L_{2} / d \lambda$ are negative.
} 
When testing the second best model, we find that when the market interest rate is high, or when the cane value is low, the mill will raise its interest rate. Farmers' borrowing is then discouraged as a consequence. However, restricted to the low variation of the cane value in a year, the second phenomenon is observed only when year dummies are dropped.

The low interest rate pays off only if the mill also suppresses the cane price. The only prediction that our model can make about the cane price is a conditional one: cane prices increase with the paddy ratio when the mill's interest rate increases with the paddy ratio. While the paddy cane price passes the test at the $5 \%$ level, the cane price in dry fields increases with the paddy ratio insignificantly. Overall, we demonstrate that the terms in the contracts are largely consistent with the second best interest rate and the optimal cane price.

\section{Appendix}

We first prove some useful lemmas.

Lemma 1. A type $t$ farmer will be induced to invest efficiently if $i=i_{t}^{*}$, and to under-(over-)invest if $i>(<) i_{t}^{*}$.

\section{Proof of lemma 1:}

If $i=i_{t}^{*}$, then the optimal price in problem (3) is the price in the benchmark case or $P_{t}=P_{t}^{*}$. Therefore, $S^{*}$ is achieved.

Define $P_{t}^{\prime}$ to be the cane price that induces efficient investment for type $t$ when the interest rate is $i$, i.e.,

$$
\frac{P_{t}^{\prime}}{1+i}=\frac{P_{t}^{*}}{1+i_{t}^{*}}=\frac{v}{1+r}
$$

If $i<i_{t}^{*}$, then $P_{t}^{\prime}<P_{t}^{*}$, therefore $(1+i) /(1+r)=P_{t}^{\prime} / v<P_{t}^{*} / v=A_{t} / S^{*}$. The optimal price $P_{t}$ in problem (3) cannot be $P_{t}^{\prime}$ because in this case the ratio of the farmer's profit to the maximal joint surplus $(1+i) /(1+r)$ is less than $A_{t} / S^{*}$, implying the farmer's profit is less than his reservation, which is impossible. A fortiori, the optimal price cannot be less than $P_{t}^{\prime}$ because then 
the farmer's profit will be even less. Since in optimum $P_{t}>P_{t}^{\prime}$, the farmer will overinvest.

If $i>i_{t}^{*}$, then $P_{t}^{\prime}>P_{t}^{*}$, therefore $(1+i) /(1+r)=P_{t}^{\prime} / v>P_{t}^{*} / v=A_{t} / S^{*}$. The optimal price in problem (3) cannot be $P_{t}^{\prime}$ because in this case the ratio of the farmer's profit to the maximal joint surplus $(1+i) /(1+r)$ is greater than $A_{t} / S^{*}$, implying the farmer's profit is greater than his reservation. To lower the price a little below $P_{t}^{\prime}$ will lower the farmer's profit with no firstorder effect on the joint profit. Therefore, the mill's profit can be increased. A fortiori, the optimal price cannot be greater than $P_{t}^{\prime}$ because then the farmer's profit will be even more while the joint profit will be even less. Since in optimum $P_{t}<P_{t}^{\prime}$, the farmer will underinvest.

Recall that $\pi_{m t}^{*}$ is the maximized value of $\pi_{m t}$ in problem (3).

Lemma 2. $\pi_{m t}^{*}$ is single-peaked at $i_{t}^{*}$, i.e. $d \pi_{m t}^{*} / d i<(=,>) 0$, if $i>(=,<) i_{t}^{*}$.

\section{Proof of lemma 2:}

To simply notations, $L_{t}$ and $P_{t}$ will be short-handed as $L$ and $P$ below. The Lagrange formulation of problem (3) is:

$$
\begin{aligned}
\Gamma= & v f(L)-(1+r) L-P f(L)+(1+i) L \\
& +\alpha\left[f^{\prime}(L)-\frac{1+i}{P}\right]+\beta\left[P f(L)-(1+i) L-A_{t}\right] .
\end{aligned}
$$

The FOC's are:

$$
\begin{aligned}
& \frac{\partial \Gamma}{\partial P}=-f(L)+\frac{\alpha(1+i)}{P^{2}}+\beta f(L)=0 \\
& \frac{\partial \Gamma}{\partial L}=v f^{\prime}(L)-(1+r)+\alpha f^{\prime \prime}(L)+\beta\left[P f^{\prime}(L)-(1+i)\right]=0 .
\end{aligned}
$$

By envelope theorem,

$$
\frac{d \pi_{m t}^{*}}{d i}=\frac{\partial \Gamma}{\partial i}=L-\frac{\alpha}{P}-\beta L .
$$

From (11),

$$
\alpha=\frac{P f(L)}{f^{\prime}(L)}(1-\beta) .
$$


To substitute $\alpha$ above into (12), we have:

$$
\beta=\frac{f^{\prime}(L)}{P f(L) f^{\prime \prime}(L)}\left[v f^{\prime}(L)-(1+r)\right]+1
$$

With the above two equations, (13) can then be rewritten as:

$$
\begin{aligned}
& \frac{d \pi_{m t}^{*}}{d i}=\left(\frac{f(L)}{f^{\prime}(L)}-L\right) \frac{f^{\prime}(L)}{P f(L) f^{\prime \prime}(L)}\left[v f^{\prime}(L)-(1+r)\right] . \\
& (+) \quad(-)
\end{aligned}
$$

Under assumption 1, the first term at the right hand side is positive, and the second term negative. Therefore, the sign of $d \pi_{m t}^{*} / d i$ is completely up to the sign of $v f^{\prime}(L)-(1+r)$. Lemma 1 then helps complete the proof.

Lemma 3. In the first best model, the optimal interest rate must satisfy $i \in\left(i_{1}^{*}, i_{2}^{*}\right)$.

\section{Proof of lemma 3:}

Recall from (1) that $i_{2}^{*}>i_{1}^{*}$. From lemma 2, $\forall t, d \pi_{m t}^{*} / d i<(>) 0$, when $i>i_{2}^{*}\left(i<i_{1}^{*}\right)$. Therefore lowering (raising) interest $i$ to $i_{2}^{*}$ increases a mill's profit when $i>i_{2}^{*}\left(i<i_{1}^{*}\right)$. Hence the optimal interest rate must lie between $i_{1}^{*}$ and $i_{2}^{*}$. Moreover, it is never optimal to set the interest exactly equal to $i_{2}^{*}\left(i_{1}^{*}\right)$ because lowering (raising) the interest has no first order effect on the mill's profit from farmers of type 2 (type 1 ) but increases its profit from farmers of type 1 (type 2 ).

\section{Proof of proposition 2:}

Lemma 3 establishes that the optimal common interest rate is the weighted average of $i_{1}^{*}$ and $i_{2}^{*}$. Proposition 2 then follows directly.

\section{Proof of proposition 3:}

Lemmas 1 and 3 together imply proposition 3 .

We now prove a useful lemma to solve problem (3). Consider a farmer of a given type. We approach problem (3) indirectly through two other related 
problems. Let problem $(\overline{3})$ be the same as problem (3), except that the weak inequality in the IR constraint is changed to an equality. That is, the farmer's profit is always his opportunity cost in problem $(\overline{3})$. Let problem $(\widehat{3})$ be problem (3) without the IR constraint. Hence the farmer's profit could be anything in problem $(\widehat{3})$. Denote $\bar{P}_{t}(i)$ and $\widehat{P}_{t}(i)$ as the cane prices solved from problem $(\overline{3})$ and problem $(\widehat{3})$, respectively.

Lemma 4. Under assumptions 1 and 2, (a) $\widehat{P}_{t}(i)$ exists and is uniquely determined by the local condition. (b) The optimal cane price in problem (3) $P_{t}$ satisfies that $P_{t}=\max \left\{\widehat{P}_{t}(i), \bar{P}_{t}(i)\right\}$.

\section{Proof of lemma 4:}

(a) The following is a marginal analysis of the loan. By (2), when the IR constraint is ignored, problem (3) becomes:

$$
\max _{L_{t}} \pi_{m t}=v f\left(L_{t}\right)-(1+r) L_{t}-\frac{1+i}{f^{\prime}\left(L_{t}\right)} f\left(L_{t}\right)+(1+i) L_{t} .
$$

The first order condition satisfies:

$$
v f^{\prime}\left(L_{t}\right)-(1+r)=(1+i)\left(\frac{-f\left(L_{t}\right) f^{\prime \prime}\left(L_{t}\right)}{\left(f^{\prime}\left(L_{t}\right)\right)^{2}}\right) .
$$

The left hand side (LHS) of the equation decreases monotonically from infinity to $-(1+r)$ as $L_{t}$ increases from 0 to infinity. By assumptions 1 and 2, the right hand side (RHS) of the equation is always positive and monotonically increases as $L_{t}$ increases. Therefore, the LHS equals the RHS at one unique level $L_{t}$, denoted $\widehat{L}_{t}$, as shown in figure 6 . Moreover, the LHS is greater (smaller) than the RHS when $L_{t}$ is smaller (greater) than $\widehat{L}_{t}$, therefore, $\widehat{L}_{t}$ is the maximizer. $\widehat{P}_{t}(i)$ is then solved from (2) with $L_{t}=\widehat{L}_{t}$.

(b) Suppose the IR constraint is satisfied when the cane price is set at $\widehat{P}_{t}(i)$, then $\widehat{P}_{t}(i)$ is clearly the optimal price. Otherwise, the mill has to raise the cane price above $\widehat{P}_{t}(i)$ to meet the IR constraint. From part (a), $d \pi_{m t} / d L_{t}<0$ when $L_{t}>\widehat{L}_{t}$. From (2), $P_{t}$ strictly increases in $L_{t}$. Therefore $d \pi_{m t} / d P_{t}<0, \forall P_{t}>\widehat{P}_{t}(i)$. Hence while increasing the cane price enhances the farmer's profit, it always reduces the mill's profit when $P_{t}>\widehat{P}_{t}(i)$. Thus, the mill will only raise the cane price up to $\bar{P}_{t}(i)$. 


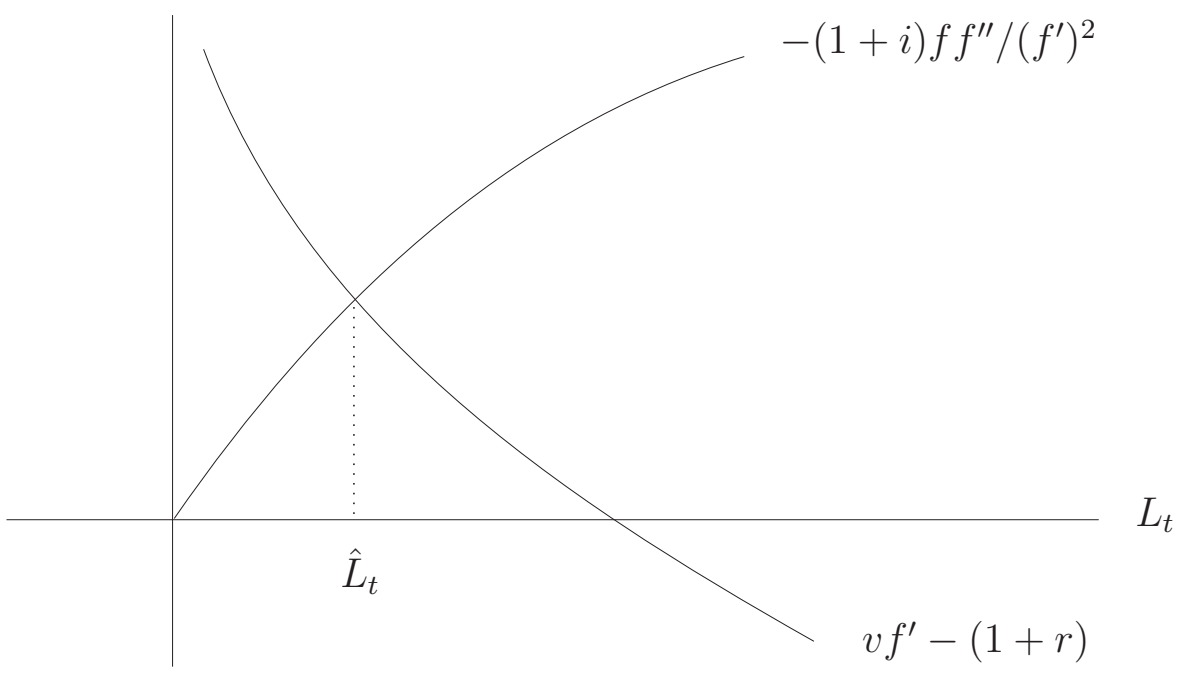

Figure 6: Determination of $L_{t}$ when the IR Constraint Is Not Binding

\section{Proof of proposition 4:}

From lemma 4 (b), $P_{t}=\max \left\{\widehat{P}_{t}(i), \bar{P}_{t}(i)\right\}$. Consider two interest rates, $i_{1}$ and $i_{2}$, with $i_{1}<i_{2}$. We need to show that the optimal price in problem (3) when the interest is $i_{1}$ is strictly lower than that when the interest is $i_{2}$, holding all other things equal. To satisfy the IR constraint, when the interest is higher, the price has to be higher, so it is clear that $\bar{P}_{t}\left(i_{1}\right)<\bar{P}_{t}\left(i_{2}\right)$. The following will show that $\widehat{P}_{t}\left(i_{1}\right)<\widehat{P}_{t}\left(i_{2}\right)$.

From lemma 4 (a), $\widehat{P}_{t}(i)$ is uniquely determined by the FOC:

$$
\left.\frac{d \pi_{m t}}{d P_{t}}\right|_{P_{t}=\widehat{P}_{t}(i)}=-f\left(L_{t}\right)+\left.\frac{d L_{t}}{d P_{t}}\left[v f^{\prime}\left(L_{t}\right)-(1+r)\right]\right|_{P_{t}=\widehat{P}_{t}(i)}=0
$$

From (2),

therefore when the interest rate is $i_{1}$,

$$
\frac{d L_{t}}{d P_{t}}=\frac{-f^{\prime}\left(L_{t}\right)}{P_{t} f^{\prime \prime}\left(L_{t}\right)}=\frac{-\left(f^{\prime}\left(L_{t}\right)\right)^{2}}{(1+i) f^{\prime \prime}\left(L_{t}\right)},
$$

$$
\left.\frac{d \pi_{m t}}{d P_{t}}\right|_{P_{t}=\widehat{P}_{t}\left(i_{1}\right)}=\left.f\left(L_{t}\right)\left[-1-\frac{\left(f^{\prime}\left(L_{t}\right)\right)^{2}}{f\left(L_{t}\right) f^{\prime \prime}\left(L_{t}\right)} \frac{v f^{\prime}\left(L_{t}\right)-(1+r)}{1+i_{1}}\right]\right|_{P_{t}=\widehat{P}_{t}\left(i_{1}\right)}=0 .
$$

The following will show that when the interest rate changes to $i_{2}$, if $P_{t}$ remains $\widehat{P}_{t}\left(i_{1}\right)$, then $d \pi_{m t} /\left.d P_{t}\right|_{P_{t}=\widehat{P}_{t}\left(i_{1}\right)}>0$. First, a pure increase in $i$ causes $L_{t}$ to 
decrease by (2), and $-\left(f^{\prime}\left(L_{t}\right)\right)^{2} / f\left(L_{t}\right) f^{\prime \prime}\left(L_{t}\right)$ to increase under assumption 2 . If $P_{t}$ remains, by (2) one can derive:

$$
\frac{d L_{t}}{d i}=\frac{1}{P_{t} f^{\prime \prime}\left(L_{t}\right)},
$$

and this implies

$$
\frac{d\left(\frac{v f^{\prime}\left(L_{t}\right)-(1+r)}{1+i}\right)}{d i}=\frac{1+r}{(1+i)^{2}}>0 .
$$

Hence, when $i=i_{2}, d \pi_{m t} /\left.d P_{t}\right|_{P_{t}=\widehat{P}_{t}\left(i_{1}\right)}>0$. From lemma 4 (a), this implies that $\widehat{P}_{t}\left(i_{1}\right)<\widehat{P}_{t}\left(i_{2}\right)$.

\section{Proof of proposition 5:}

For any $i<r$, the farmer has an incentive to take advantage of the mill's cheap loan to arbitrage. Because monitoring is costly, given $i$, the optimal catching probability, $q$, is just high enough so that a farmer is indifferent between cheating and not cheating. That is, (5) always holds as an equality. So we could consider the catching probability $q$ as a function of $i$, and clearly $q^{\prime}(i)<0$, i.e., the higher the interest, the lower the catching probability to deter farmers from arbitraging.

Moreover, $P_{t}$ is also immediately determined in problem (3) once $i$ is given. Thus we could view the mill's profit function purely a function of $i$, i.e. $\pi_{M}^{S B}(i) \equiv \pi_{M}^{S B}\left(i, P_{1}(i), P_{2}(i), q(i)\right)$ and $\pi_{M}^{F B}(i) \equiv \pi_{M}^{F B}\left(i, P_{1}(i), P_{2}(i)\right)$.

We shall first use a local argument to show that $\exists i^{\prime}>i^{F B}$ such that $\pi_{M}^{S B}\left(i^{\prime}\right)>\pi_{M}^{S B}\left(i^{F B}\right)$. We then argue globally that $i^{S B} \nless i^{F B}$.

From (6),

$$
\left.\frac{d \pi_{M}^{S B}}{d i}\right|_{i=i^{F B}}=\left.\frac{d \pi_{M}^{F B}}{d i}\right|_{i=i^{F B}}-\left.\frac{d c}{d q} \frac{d q}{d i}\right|_{i=i^{F B}}>0
$$

This is because $d \pi_{M}^{F B} /\left.d i\right|_{i=i^{F B}}=0$ and $i^{F B}<r$ (by proposition 2) so that $q\left(i^{F B}\right)>0$ and $d q /\left.d i\right|_{i=i^{F B}}<0$. It follows that in the neighborhood of $i^{F B}$, $\exists i^{\prime}>i^{F B}$ such that $\pi_{M}^{S B}\left(i^{\prime}\right)>\pi_{M}^{S B}\left(i^{F B}\right)$.

Furthermore, $\forall i^{\prime \prime}<i^{F B}$, we have $\pi_{M}^{F B}\left(i^{\prime \prime}\right) \leq \pi_{M}^{F B}\left(i^{F B}\right)$ and $c\left(q\left(i^{\prime \prime}\right)\right)>$ $c\left(q\left(i^{F B}\right)\right.$ ) (because $\left.i^{F B}<r\right)$. It follows that $\pi_{M}^{S B}\left(i^{\prime \prime}\right)<\pi_{M}^{S B}\left(i^{F B}\right)$. Thus $i^{S B} \nless i^{F B}$. 


\section{Proof of proposition 6:}

(a) Note that $\forall i^{\prime}>r, d \pi_{M}^{F B} /\left.d i\right|_{i=i^{\prime}}<0$ and $c\left(q\left(i^{\prime}\right)\right)=0$. It follows from (6) that $i^{S B} \ngtr r$.

(b) From (6),

$$
\left.\frac{d \pi_{M}^{S B}}{d i}\right|_{i \rightarrow r^{-}}=\left.\frac{d \pi_{M}^{F B}}{d i}\right|_{i \rightarrow r^{-}}-\left.\frac{d c}{d i}\right|_{i \rightarrow r^{-}} .
$$

Both the first term and the second term (without the minus sign) at the RHS are negative. When the absolute value of the first term exceeds that of the second term, $d \pi_{M}^{S B} /\left.d i\right|_{i \rightarrow r^{-}}$is negative. In this case, decreasing the interest from $r$ increases the mill's profit, hence we have $i^{S B}<r$. Noting that $d c /\left.d i\right|_{i \rightarrow r^{-}}=\left.(d c / d q)(d q / d i)\right|_{i \rightarrow r^{-}}=-c^{\prime}(0) /(k-r)$, the claim is thus established.

We first prove a useful lemma. Recall that $\pi_{m t}^{*}$ is mill's maximum profit from type $t$ farmer in (3) for a given interest rate $i$. Thus,

$$
\pi_{M}^{S B}=(1-\lambda) \pi_{m 1}^{*}+\lambda \pi_{m 2}^{*}-c(q) .
$$

Lemma 5. (a) $d \pi_{m t}^{*} / d i$ strictly decreases in $v, \forall i$, and $t=1,2$. (b) $d \pi_{m t}^{*} / d i$ strictly increases in $r, \forall i$, and $t=1,2$.

Proof: We shall only prove part (a). The same argument could be applied to prove part (b). From lemma 4 (b), given $i, \pi_{m t}^{*}$ in problem (3) is either solved from problem $(\overline{3})$, or from problem $(\widehat{3})$. We shall split the discussion into the following 3 cases: For a given $i$, (i) $\forall v, \pi_{m t}^{*}$ is solved from problem $(\overline{3})$. (ii) $\forall v, \pi_{m t}^{*}$ is solved from problem $(\widehat{3})$. (iii) $\pi_{m t}^{*}$ is solved from problem $(\overline{3})$ for some $v$ 's, and from problem $(\widehat{3})$ for other $v$ 's. Before proceeding, recall that $d \pi_{m t}^{*} / d i$ is already calculated in (15).

Case (i). In problem $(\overline{3})$, the IR constraint is always binding. When $v$ increases, if $i$ remains fixed, to keep the IR constraint not violated, the cane price $P_{t}$ will not change. Under the same contract, a farmer will make the same loan $L_{t}$. It follows that when $v$ increases, the first two terms in (15) remain the same, while the last term increases.

In $(15)$, when $v f^{\prime}-(1+r)>(<) 0, d \pi_{m t}^{*} / d i<(>) 0$. So an increase in $v f^{\prime}-(1+r)$ will cause $d \pi_{m t}^{*} / d i$ to decrease. When $v f^{\prime}-(1+r)=0$, $d \pi_{m t}^{*} / d i=0$, an increase in $v f^{\prime}-(1+r)$ will turn $d \pi_{m t}^{*} / d i$ negative. 
Case (ii). In problem $(\widehat{3})$, the farmer's IR constraint is not binding. In this case, $\beta=0$ in (14) so the second term in (15) is the negative inverse of the third term, and $L_{t}$ is determined by the intersection of the two curves in figure 6. (15) becomes simply:

$$
\frac{d \pi_{m t}^{*}}{d i}=L_{t}-\frac{f}{f^{\prime}}
$$

Because $d\left(L_{t}-f / f^{\prime}\right) / d L_{t}<0$, so $d \pi_{m t}^{*} / d i$ decreases with $L_{t}$. When $v$ increases and $i$ remains fixed, the curve of $v f^{\prime}-(1+r)$ in figure 6 shifts up. This causes $L_{t}$ to increase and $d \pi_{m t}^{*} / d i$ to decrease.

Case (iii). We shall first argue that $\exists \bar{v}$ such that $\forall v<\bar{v}$, problem $(\overline{3})$ applies and $\forall v \geq \bar{v}$, problem $(\widehat{3})$ applies.

The very reason that problem $(\widehat{3})$ only applies for some $v$ is because when we solve problem $(\widehat{3})$ for all possible $v$ 's, sometimes the farmer's profit $\pi_{f t} \geq A_{t}$, and sometimes $\pi_{f t}<A_{t}$. As argued in case (ii), in problem ( $\left.\widehat{3}\right)$, when $v$ increases, $L_{t}$ will increase. Because the interest rate $i$ is fixed, by the IC constraint, it must be an increase in $P_{t}$ that induces $L_{t}$ to increase. In sum, when $v$ increases, the contract in problem $(\widehat{3})$ becomes more favorable to the farmer, i.e. $\pi_{f t}$ increases with $v$. Thus, let $\bar{v}$ be such that $\pi_{f t}=A_{t}$ in problem $(\widehat{3})$ when $v=\bar{v}$. We have $\pi_{f t}>(<) A_{t}, \forall v>(<) \bar{v}$. So problem $(\widehat{3})$ applies iff $v \geq \bar{v}$.

The argument in the previous two cases helps establish that $d \pi_{m t}^{*} / d i$ strictly decreases in $v, \forall v \neq \bar{v}$. To complete our proof, we shall argue that the negatively sloped curves $d \pi_{m t}^{*} / d i$ 's (drawn over $v$ ) in problem $(\overline{3})$ and in problem $(\widehat{3})$ intersect at $v=\bar{v}$ so that $d \pi_{m t}^{*} / d i$ at $v=\bar{v}$ is well-defined. In view of $(15), d \pi_{m t}^{*} / d i$ is only up to $L_{t}$. So we have to show that the optimal $L_{t}$ in two problems are the same when $v=\bar{v}$. Note that in problem (3), $\pi_{f t}=A_{t}$ when $v=\bar{v}$. Given the interest rate $i$, there is a unique cane price $P_{t}$ that makes a farmer earns exactly $A_{t}$. Hence when $v=\bar{v}, P_{t}$ and the induced $L_{t}$ are the same in the two problems.

\section{Proof of proposition 7:}

We first prove that the when the value of cane increases, the second best rate decreases. 
Consider that $v$ increases from $v^{\prime}$ to $v^{\prime \prime}$, and the optimal interest rate changes from $i^{\prime}$ to $i^{\prime \prime}$. In view of (18), when $v$ increases from $v^{\prime}$ to $v^{\prime \prime}$, if the interest rate still remains at $i^{\prime}$, then by lemma 5 , since $d \pi_{m t}^{*} / d i$ strictly decreases, $\exists \epsilon>0$, such that $\left.\pi_{M}^{S B}\right|_{i=i^{\prime}-\epsilon}>\left.\pi_{M}^{S B}\right|_{i=i^{\prime}}$. In the following, we shall argue that $i^{\prime \prime} \ngtr i^{\prime}$.

Suppose $i^{\prime \prime}>i^{\prime}$. When $v=v^{\prime}$, we have:

$$
(1-\lambda) \pi_{m 1}^{*}+\lambda \pi_{m 2}^{*}-\left.c(q)\right|_{i=i^{\prime}} \geq(1-\lambda) \pi_{m 1}^{*}+\lambda \pi_{m 2}^{*}-\left.c(q)\right|_{i=i^{\prime \prime}} .
$$

This inequality could be rearranged to be:

$$
-(1-\lambda) \int_{i^{\prime}}^{i^{\prime \prime}} \frac{d \pi_{m 1}^{*}}{d i} d i-\left.\lambda \int_{i^{\prime}}^{i^{\prime \prime}} \frac{d \pi_{m 2}^{*}}{d i} d i\right|_{v=v^{\prime}} \geq\left. c(q)\right|_{i=i^{\prime}}-\left.c(q)\right|_{i=i^{\prime \prime}} .
$$

By lemma 5 , since $d \pi_{m t} / d i$ strictly decreases in $v$, it leads to:

$$
-(1-\lambda) \int_{i^{\prime}}^{i^{\prime \prime}} \frac{d \pi_{m 1}^{*}}{d i} d i-\left.\lambda \int_{i^{\prime}}^{i^{\prime \prime}} \frac{d \pi_{m 2}^{*}}{d i} d i\right|_{v=v^{\prime \prime}}>\left.c(q)\right|_{i=i^{\prime}}-\left.c(q)\right|_{i=i^{\prime \prime}} .
$$

That implies when $v=v^{\prime \prime}, \pi_{M}^{S B}\left(i^{\prime \prime}\right)<\pi_{M}^{S B}\left(i^{\prime}\right)$, a contradiction to $i^{\prime \prime}$ being optimal at $v=v^{\prime \prime}$.

We now prove that when the value of cane increases, the production loans also increase.

Recall from lemma 4 (b) that $L_{t}$ is either solved from problem $(\overline{3})$ or $(\widehat{3})$. Consider that when $v$ increases from $v^{\prime}$ to $v^{\prime \prime}, i^{S B}$ decreases from $i^{\prime}$ to $i^{\prime \prime}$ as just argued and the optimal $L_{t}$ in problem (3) changes from $L_{t}^{\prime}$ to $L_{t}^{\prime \prime}$. In the following, we shall split the discussion into 4 cases to argue that $L_{t}^{\prime \prime}>L_{t}^{\prime}$.

Case (i). Both $L_{t}^{\prime}$ and $L_{t}^{\prime \prime}$ are solved from problem $(\overline{3})$. Because the IR constraint is binding in problem $(\overline{3})$, when $v$ increases, $P_{t}$ will decrease along with the interest rate. If the ratio of $P_{t} /(1+i)$ remains the same after these changes, the farmer's profit will decrease at the same rate at which $P_{t}$ and $1+i$ decrease. So the ratio of $P_{t} /(1+i)$ must increase to raise the farmer's profit back to $A_{t}$, and an increase in $P_{t} /(1+i)$ will induce the farmer to borrow more.

Case (ii). Both $L_{t}^{\prime}$ and $L_{t}^{\prime \prime}$ are solved from problem ( $\left.\widehat{3}\right)$. In this case, the IR constraint is not binding, and $L_{t}$ is determined as figure 6 shows. When $v$ increases and $i$ decreases, the curve of $-(1+i) f f^{\prime \prime} /\left(f^{\prime}\right)^{2}$ will shift down 
and the curve of $v f^{\prime}-(1+r)$ will shift up in figure 6. $L_{t}$ will increase as a result.

Case (iii). $L_{t}^{\prime}$ is solved from problem $(\widehat{3})$, and $L_{t}^{\prime \prime}$ is solved from problem $(\overline{3})$. Let $L_{t}^{\prime \prime \prime}$ be the optimal $L_{t}$ in problem $(\widehat{3})$ when $v=v^{\prime \prime}$ and $i=i^{\prime \prime}$. As argued in case (ii), $L_{t}^{\prime \prime \prime}>L_{t}^{\prime}$. If $L_{t}^{\prime \prime \prime} \neq L_{t}^{\prime \prime}$, it must be that along with $i^{\prime \prime}$, the optimal $P_{t}$ that induces this $L_{t}^{\prime \prime \prime}$ in problem $(\widehat{3})$ fails to grant the farmer a profit as high as his opportunity cost. So $P_{t}$ has to be raised to meet the IR constraint. Accompanying the increase in $P_{t}, L_{t}$ increases from $L_{t}^{\prime \prime \prime}$ to $L_{t}^{\prime \prime}$. Hence, $L_{t}^{\prime \prime}>L_{t}^{\prime}$.

Case (iv). $L_{t}^{\prime}$ is solved from problem $(\overline{3})$, and $L_{t}^{\prime \prime}$ is solved from problem $(\widehat{3})$. Let $\widetilde{L}_{t}$ be the optimal $L_{t}$ in problem $(\overline{3})$ when $v=v^{\prime \prime}$ and $i=i^{\prime \prime}$. As argued in case (i), $\widetilde{L}_{t}>L_{t}^{\prime}$. If $\widetilde{L}_{t} \neq L_{t}^{\prime \prime}$, it must be that along with $i^{\prime \prime}$, the optimal $P_{t}$ that induces this $L_{t}^{\prime \prime}$ in problem $(\widehat{3})$ grants the farmer a higher profit than his opportunity cost. Therefore, this $P_{t}$ is higher than what induces $\widetilde{L}_{t}$ in problem $(\overline{3})$. So $L_{t}^{\prime \prime}>\widetilde{L}_{t}$.

\section{Proof of proposition 8:}

We first prove that the second best rate increases with the market rate when the condition is satisfied. In view of (18), when $r$ increases, $d \pi_{m t}^{*} / d i$ increases, for $t=1,2$ by lemma 5 . Moreover, $d c(q) / d i$ also changes because $q$ changes as dictated by the no-arbitrage condition (5). Repeating the logic of proposition 7 's proof with lemma 5 (b), we have:

$$
\frac{d i}{d r}>0, \quad \text { if } \frac{d^{2} c}{d i d r} \leq 0 .
$$

In the following, we shall explain that when $c_{q q} \geq c_{q} /(1-q)$, then $d^{2} c /$ didir $\leq$ 0 .

Because the no-arbitrage condition (5) always holds as an equality, we have:

$$
q=\frac{r-i}{k-i}
$$

and

$$
\frac{d q}{d i}=-\frac{k-r}{(k-i)^{2}}
$$


The monitoring cost $c(q)$ is fully up to $q$, which in turns, depends on $i$, so we have:

$$
\begin{aligned}
\frac{d \frac{d c}{d i}}{d r} & =\frac{d c_{q} \frac{d q}{d i}}{d r} \\
& =c_{q q} \frac{\partial q}{\partial r} \frac{d q}{d i}+c_{q} \frac{d \frac{d q}{d i}}{d r} \\
& =\frac{1}{(k-i)^{2}}\left(c_{q}-c_{q q} \frac{k-r}{k-i}\right) .
\end{aligned}
$$

The last equality follows from (19) and (20). Recall that $k>r$ and $r \geq i$ when the moral hazard problem is a concern. So, $0<(k-r) /(k-i) \leq 1$. When $c_{q q}$ is sufficiently high, i.e. when

$$
c_{q q} \geq \frac{c_{q}}{(k-r) /(k-i)},
$$

we have $d^{2} c /$ didir $\leq 0$. From (19), $i=(r-q k) /(1-q)$. So the above inequality is the same as $c_{q q} \geq c_{q} /(1-q)$.

As for why the production loans decrease with the market rate, the same logic of the second part of proposition 7's proof works here.

\section{Proof of proposition 9:}

(a) Given $i, P_{t}$ is completely independent of $\lambda$ when $\pi_{m t}$ is maximized. From proposition $4, \partial P_{t} / \partial i>0$. This establishes (a).

(b) An argument simplified from the proof of the second part of proposition 7 applies here. Just change to consider $i^{S B}$ decreasing from $i^{\prime}$ to $i^{\prime \prime}$ when $\lambda$ decreases, and have $v^{\prime}=v^{\prime \prime}$ in the proof of proposition 7 . The same steps establish that $L_{t}$ increases when $i$ decreases.

\section{References}

Bardhan, P.K. and A. Rudra (1978), "Interlinkage of Land, Labour and Credit Relation: An Analysis of Village Survey Data in East india", Economic and Political Weekly, 367-84. 
Bardhan, P.K. and C. Udry (1999), "Development Microeconomics", Oxford.

Basu, C. Bell, K. and A. Chaudhuri (2000), "Interlinkage, Limited Liability and Strategic Interaction", Journal of Economic Behavior and Organization, 42, 445-462.

Bell, C. (1988), "Credit Markets and interlinked Transactions in H. Chenery and T. N. Srinivasan (eds.)", in Handbook of Development Economics, vol. 1, Amsterdam: Elsevier Science Publishers B.V.

Bell, T.N. Srinvivasan, C. and C. Udry (1997), "Rationing, Spillover, and Interlinking in Credit Markets: The Case of Rural Punjab", Oxford Economic Papers, 49, 557-585.

Bhaduri, A. (1977), "On the Formation of Usurious Interest Rates in Backward Agriculture", Cambridge Journal of Economics, 341-52.

Bhalla, S. (1976), "New Relations of Production in Haryana Agriculture", Economic and Political Weekly, 95.

Bottomley, A. (1963), "The Premium for Risk as a Determinant of Interest Rates in Underdeveloped Rural Areas", Quarterly Journal of Economics, $637-47$.

Braverman, A. and Joseph E. Stiglitz (1982), "Sharecropping and the Interlinking of Agrarian Markets", American Economic Review, 695-715.

Chakrabarty, D. and A. Chaudhuri (2001), "Formal and Informal Sector Credit Institutions and Interlinkage", Oxford Economic Papers, 46, 313325.

Chaudhuri, S. and M.R. Gupta (1995), "Price Uncertainty and CreditProduct Interlinkage: An Extension of the Analysis of Gangopadhyay and Sengupta", The Journal of International Trade 8 Economic Development, 4, 93-113.

Civil Affairs Statistical Annual (1929-1938), Interior Bureau, Taiwan Government-General.

Fabella, R.V. (1992), "Price Uncertainty and Trader-Farmer Linkage", Journal of Public Economics, 47, 391-99.

Gangopadhyay, Shubhashis and Kunal Sengupta (1987), "Small Farmers, Moneylenders and Trading Activity", Oxford Economic Papers, 333-42.

Ray, D. (1998), Development Economics, Princeton: Princeton University Press.

Sadoulet, E. (1992), "Labor-Service Tenancy Contracts in a Latin American 
Context", American Economic Review, 82, 1031-1042.

Sugar Industry Addendum (1928-1944), Taiwan Sugar Industry Research Committee.

Survey of Agricultural Financing, Basic Agricultural Survey, Vol. 43 (1941), Agriculture and Industry Bureau, Taiwan Government-General, Taipei.

Tainan Chow Statistics Book (1929), Tainan Chow Official Document Office.

Taiwan Financial Annual (1934-1942), Taiwan Government-General.

Taiwan Rice Annual (1934-1942), Agriculture and Industry Bureau, Taiwan Government-General.

Taiwan Sugar Statistics (1911-1943), Agriculture and Industry Bureau, Taiwan Government-General.

Taiwan Province: Statistical Summary of the Past 51 Years (1946), Provincial Bureau of Accounting and Statistics.

Wu, Tsong-min (2005), "Taiwan's Consumer Price Index in the Rural Area: 1902-1941", Taiwan Economic Review, 33(4), 321-55.

Yanaihara, Tadao (1929), Taiwan under the Japanese Colonialism, Tokyo: Iwanami Shoten, 2nd print in 1934 edn. 